\title{
Asteroids' physical models from combined dense and sparse photometry and scaling of the YORP effect by the observed obliquity distribution ${ }^{\star}$
}

\author{
J. Hanuš ${ }^{1}$, J. Ďurech ${ }^{1}$, M. Brož1 ${ }^{1}$ A. Marciniak ${ }^{2}$, B. D. Warner $^{3}$, F. Pilcher ${ }^{4}$, R. Stephens ${ }^{5}$, R. Behrend ${ }^{6}$, B. Carry ${ }^{7}$,
} D. Čapek ${ }^{8}$, P. Antonini ${ }^{9}$, M. Audejean ${ }^{10}$, K. Augustesen ${ }^{11}$, E. Barbotin ${ }^{12}$, P. Baudouin ${ }^{13}$, A. Bayol ${ }^{11}$, L. Bernasconi ${ }^{14}$, W. Borczyk ${ }^{2}$, J.-G. Bosch ${ }^{15}$, E. Brochard ${ }^{16}$, L. Brunetto ${ }^{17}$, S. Casulli ${ }^{18}$, A. Cazenave $^{12}$, S. Charbonnel $^{12}$, B. Christophe ${ }^{19}$, F. Colas ${ }^{20}$, J. Coloma ${ }^{21}$, M. Conjat ${ }^{22}$, W. Cooney ${ }^{23}$, H. Correira ${ }^{24}$, V. Cotrez ${ }^{25}$, A. Coupier ${ }^{11}$, R. Crippa $^{26}$, M. Cristofanelli ${ }^{17}$, Ch. Dalmas ${ }^{11}$, C. Danavaro ${ }^{11}$, C. Demeautis ${ }^{27}$, T. Droege ${ }^{28}$, R. Durkee ${ }^{29}$, N. Esseiva ${ }^{30}$,

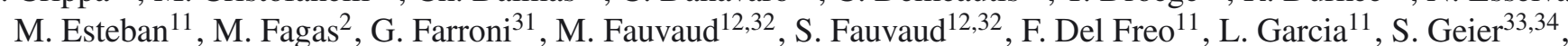

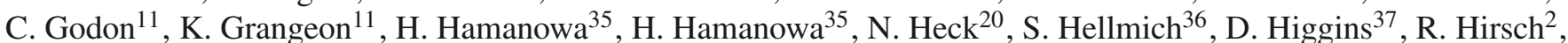
M. Husarik ${ }^{38}$, T. Itkonen ${ }^{39}$, O. Jade ${ }^{11}$, K. Kamiński ${ }^{2}$, P. Kankiewicz ${ }^{40}$, A. Klotz ${ }^{41,42}$, R. A. Koff ${ }^{43}$, A. Kryszczyńska ${ }^{2}$, T. Kwiatkowski ${ }^{2}$, A. Laffont ${ }^{11}$, A. Leroy ${ }^{12}$, J. Lecacheux ${ }^{44}$, Y. Leonie ${ }^{11}$, C. Leyrat ${ }^{44}$, F. Manzini ${ }^{45}$, A. Martin ${ }^{11}$, G. Masi ${ }^{11}$, D. Matter ${ }^{11}$, J. Michałowski ${ }^{46}$, M. J. Michałowski ${ }^{47}$, T. Michałowski ${ }^{2}$, J. Michelet ${ }^{48}$, R. Michelsen ${ }^{11}$, E. Morelle ${ }^{49}$, S. Mottola ${ }^{36}$, R. Naves ${ }^{50}$, J. Nomen ${ }^{51}$, J. Oey ${ }^{52}$, W. Ogłoza ${ }^{53}$, A. Oksanen ${ }^{49}$, D. Oszkiewicz ${ }^{34,54}$, P. Pääkkönen ${ }^{39}$, M. Paiella ${ }^{11}$, H. Pallares ${ }^{11}$, J. Paulo ${ }^{11}$, M. Pavic ${ }^{11}$, B. Payet ${ }^{11}$, M. Polińska ${ }^{2}$, D. Polishook ${ }^{55}$, R. Poncy ${ }^{56}$, Y. Revaz ${ }^{57}$, C. Rinner ${ }^{31}$, M. Rocca ${ }^{11}$, A. Roche ${ }^{11}$, D. Romeuf ${ }^{11}$, R. Roy ${ }^{58}$, H. Saguin ${ }^{11}$, P. A. Salom ${ }^{11}$, S. Sanchez ${ }^{51}$, G. Santacana ${ }^{12,30}$, T. Santana-Ros ${ }^{2}$, J.-P. Sareyan ${ }^{59,60}$, K. Sobkowiak ${ }^{2}$, S. Sposetti ${ }^{61}$, D. Starkey ${ }^{62}$, R. Stoss ${ }^{51}$, J. Strajnic ${ }^{11}$, J.-P. Teng ${ }^{63}$, B. Trégon ${ }^{64,12}$, A. Vagnozzi ${ }^{65}$, F. P. Velichko ${ }^{66}$, N. Waelchli ${ }^{67}$, K. Wagrez ${ }^{11}$, and H. Wücher ${ }^{30}$

(Affiliations can be found after the references)

Received 5 November 2012 / Accepted 15 January 2013

\begin{abstract}
Context. The larger number of models of asteroid shapes and their rotational states derived by the lightcurve inversion give us better insight into both the nature of individual objects and the whole asteroid population. With a larger statistical sample we can study the physical properties of asteroid populations, such as main-belt asteroids or individual asteroid families, in more detail. Shape models can also be used in combination with other types of observational data (IR, adaptive optics images, stellar occultations), e.g., to determine sizes and thermal properties.

Aims. We use all available photometric data of asteroids to derive their physical models by the lightcurve inversion method and compare the observed pole latitude distributions of all asteroids with known convex shape models with the simulated pole latitude distributions.

Methods. We used classical dense photometric lightcurves from several sources (Uppsala Asteroid Photometric Catalogue, Palomar Transient Factory survey, and from individual observers) and sparse-in-time photometry from the U.S. Naval Observatory in Flagstaff, Catalina Sky Survey, and La Palma surveys (IAU codes 689, 703, 950) in the lightcurve inversion method to determine asteroid convex models and their rotational states. We also extended a simple dynamical model for the spin evolution of asteroids used in our previous paper.

Results. We present 119 new asteroid models derived from combined dense and sparse-in-time photometry. We discuss the reliability of asteroid shape models derived only from Catalina Sky Survey data (IAU code 703) and present 20 such models. By using different values for a scaling parameter $c_{\text {YORP }}$ (corresponds to the magnitude of the YORP momentum) in the dynamical model for the spin evolution and by comparing synthetic and observed pole-latitude distributions, we were able to constrain the typical values of the $c_{\text {YORP }}$ parameter as between 0.05 and 0.6 .
\end{abstract}

Key words. minor planets, asteroids: general

\section{Introduction}

The lightcurve inversion method (LI) was developed by Kaasalainen \& Torppa (2001) and Kaasalainen et al. (2001). This powerful tool allows us to derive physical models of asteroids (their rotational states and the shapes) from series of diskintegrated photometry.

Convex asteroid shape models can be derived from two different types of disk-integrated photometry: dense or sparse-intime. Originally, only dense photometry was used. About 20

* Table 3 is available in electronic form at http://www . aanda.org such dense lightcurves from at least four or five apparitions are necessary for a unique shape determination. By this approach, $\sim 100$ asteroid models have been derived (e.g., Kaasalainen et al. 2002; Michałowski et al. 2004; Durech et al. 2007; Marciniak et al. 2007, 2008). To significantly enlarge the number of asteroid models, sparse photometric data were studied and used in the LI. Durech et al. (2009) determined 24 asteroid models from a combination of dense data with sparse photometry from the U.S. Naval Observatory in Flagstaff (USNO-Flagstaff station, IAU code 689). Sparse data from seven astrometric surveys (including USNO-Flagstaff station) were used in the LI by 
Hanuš et al. (2011), who presented 80 asteroid models. Sixteen models were based only on sparse data, the rest on combined dense and sparse data.

Models of asteroids derived by the lightcurve inversion method are stored in the Database of Asteroid Models from Inversion Techniques (DAMIT ${ }^{1}$, Durech et al. 2010). In October 2012, models of 213 asteroids were included there.

A larger number of asteroids with derived models of their convex shapes and rotational states is important for further studies. Large statistical samples of physical parameters can tell us more about processes that take place in the asteroids' populations (near-Earth asteroids, main-belt asteroids, or asteroids in individual families). For example, an anisotropy of spin-axis directions is present in the population of main-belt asteroids with diameters $\lesssim 30 \mathrm{~km}$ (Hanuš et al. 2011), where the YORP effect ${ }^{2}$, together with collisions and mass shedding, is believed to be responsible. There are similar effects on the rotational states of main-belt binaries (Pravec et al. 2012). Convex shape models were also used in combination with stellar occultations by asteroids where global nonconvexities can be detected, and the diameter can be estimated with a typical uncertainty of $10 \%$ (see Durech et al. 2011).

In Sect. 2, we describe the dense and sparse photometric data used in the lightcurve inversion method and present new asteroid models derived from combined photometric data sets or from the sparse-in-time data from the Catalina Sky Survey Observatory (IAU code 703) alone. The reliability tests for derived models are also described. In Sect. 3, we use a theoretical model of the latitude distribution of pole directions published in Hanuš et al. (2011) in a numerical simulation to constrain the free scaling parameter $c_{\text {YORP }}$ describing our uncertainty in the shape and the magnitude of the YORP momentum.

\section{Asteroid models}

We used four main sources of dense photometric lightcurves: (i) the Uppsala Asteroid Photometric Catalogue (UAPC ${ }^{3}$, Lagerkvist et al. 1987; Piironen et al. 2001), where lightcurves for about 1000 asteroids are stored; (ii) data from a group of individual observers provided via the Minor Planet Center in the Asteroid Lightcurve Data Exchange Format (ALCDEF ${ }^{4}$, Warner et al. 2009); (iii) data from another group of individual observers available online via Courbes de rotation d'astéroïdes et de comètes $\left(\mathrm{CdR}^{5}\right)$; and (iv) data from the Palomar Transient Factory survey (PTF6 ${ }^{6}$, Rau et al. 2009). Polishook et al. (2012) recently analyzed a small fraction of PTF data and presented dense lightcurves for 624 asteroids. So far, only a fraction of photometric data from the PTF has been processed (four overlapping fields on four consecutive nights), which means that this source will become very important in the near future.

We downloaded sparse data from the AstDyS site (Asteroids - Dynamic Site ${ }^{7}$ ) and gathered sparse lightcurves from the

\footnotetext{
1 http://astro.troja.mff.cuni.cz/projects/asteroids3D

2 Yarkovsky-O'Keefe-Radzievskii-Paddack effect, a torque caused by the recoil force from anisotropic thermal emission, which can alter the rotational periods and orientation of spin axes, see e.g., Rubincam (2000), Vokrouhlický et al. (2003).

3 http://asteroid.astro.helsinki.fi/

4 http://www .minorplanet.info/alcdef.html

5 http://obswww. unige.ch/ behrend/page2cou.html

6 http://www.astro.caltech.edu/ptf/

7 http://hamilton.dm.unipi.it/
}

USNO-Flagstaff station (IAU code 689) for 1000 asteroids, from Roque de los Muchachos Observatory, La Palma (IAU code 950) for $\sim 500$ asteroids and $\gtrsim 100$ sparse data points from the Catalina Sky Survey Observatory (CSS for short, IAU code 703, Larson et al. 2003) for 4000 asteroids. We present 119 asteroid models derived from combined dense and sparse data (Sect. 2.2) and 20 models based only on CSS data (Sect. 2.3).

During the model computation, a priori information about the rotational period of the asteroid was used, which significantly reduced the volume of the multidimensional parameter space that had to be searched, and saved computational time. Period values were taken from the regularly updated Minor Planet Lightcurve Database ${ }^{8}$ (Warner et al. 2009). If the period was unknown or insecure, we searched the model over all possible period values of $2-100 \mathrm{~h}$ (usually, when only sparse data are available).

\subsection{Reliability tests}

We carefully tested the reliability of derived models. If we had several dense lightcurves and sparse data from USNO-Flagstaff station for an asteroid, we considered a model as unique if: (i) the modeled sidereal rotational period was close to the synodic rotational period determined from a single apparition dense data set (synodic period values have usually been previously published and were available in the Minor Planet Lightcurve Database); (ii) the shape model rotated close to its axis with a maximum momentum of inertia (it was in a relaxed rotational state); and (iii) models with half and double period values gave significantly worse fits.

It was necessary to apply additional tests to models derived from sparse-in-time data alone. We used the tests presented in Hanuš et al. (2011, for more details, see Sect. 3.3 there), and they were sufficient if photometry from USNO-Flagstaff station was present. In Hanuš \& Durech (2012), we have shown that reliable asteroid models can also be derived from the Catalina Sky Survey data alone, and we described a convenient procedure for how to proceed during the computation when the rotational period is unknown: the solution should be searched for all periods in an interval of $2-100 \mathrm{~h}$, and the stability of the solution should be tested for at least two different shape parametrizations ${ }^{9}$. The correct solution had to be stable for both low $(n=3)$ and high ( $n=6)$ shape resolutions. We followed these recommendations: we searched for the model in the multidimensional parameter space for shape resolutions $n=3$ and $n=6$ and checked that we derived solutions with similar rotational states. In Hanuš \& Durech (2012), we tested values $n=2,3,4,5,6$ for the shape resolution. Correct solutions (i.e., models from the CSS data were similar to the models based on different data sets) were reproduced for most values of $n$. On the other hand, incorrect solutions were derived only for values $n=6$ and sometimes also for $n=4$ or $n=5$, but never for $n=2$ or $n=3$.

\subsection{Models from combined dense and sparse data}

The shape model determination scheme was very similar to the one used in Hanuš et al. (2011). 119 new asteroid models were

\footnotetext{
8 http://cfa-www.harvard.edu/iau/lists/LightcurveDat. html

9 Shape is represented by coefficients of its expansion into spherical harmonic functions to the order $n$. We call $n$ the shape resolution, the number of shape parameters is then $(n+1)^{2}$, and our typical value for the shape resolution is $n=6$.
} 
derived because we gathered $\sim 1000$ new dense lightcurves from ALCDEF, another 1000 lightcurves from PTF, 300 from individual observers, and also additional sparse data observed by the CSS during the second half of the year 2010 and the first half of the year 2011. Derived rotational states with basic information about the photometry used for 119 asteroids are listed in Table 1. Out of them, 18 models are based only on combined sparse data from various sources, but in all cases, sparse data from USNO-Flagstaff station were present ${ }^{10}$. In Table 3, we list the references to the dense lightcurves we used for the new model determination.

Although the amount of photometric data from PTF was similar to that from ALCDEF, only two new shape models (for asteroids with numbers 52820 and 57394, see Table 1) were derived with their contribution. The first reason was a significantly worse quality of PTF data: only for 84 asteroids out of 624 were the data sufficient for determining a synodic period, while other lightcurves were noisy or burdened with systematic errors. In many cases they allowed only for an estimate of a lower limit for the lightcurve amplitude (presented in Polishook et al. 2012). The second reason was that PTF data alone were not sufficient for a unique model determination (they covered only one apparition), no other dense lightcurves were usually available, and sparse data were available for only fewer than a half of these asteroids. Many asteroids detected by the PTF survey were previously unknown.

There are previously published models available for 15 of the asteroids modeled here: (11) Parthenope, (79) Eurynome, (272) Antonia, (281) Lucretia, (351) Yrsa, (352) Gisela, (390) Alma, (787) Moskva, (852) Wladilena, (1089) Tama, (1188) Gothlandia, (1389) Onnie, (1572) Posnania, (1719) Jens, and (4954) Eric (see databases by Kryszczyńska et al. 2007; and Warner et al. 2009). As these models were usually based on limited datasets, our solutions differ from some of them substantially, while agreeing for some in the spin axis latitude or the sidereal period value. We fully confirmed previous models for six objects of that sample: the spin models of (79) Eurynome by Michałowski (1996), (787) Moskva by Svoren et al. (2009), and (1572) Posnania by Michałowski et al. (2001), as well as our preliminary solutions for (390) Alma, (1389) Onnie, and (1719) Jens obtained in Hanuš et al. (2011).

The shape models and their spin solutions can be found in the DAMIT database (Ďurech et al. 2010). We noticed that for the models based only on sparse data, their shapes tend to be very angular, with sharp edges and large planar areas, thus can be treated only as crude approximations of the real asteroid shapes. However, a substantial addition ( $\gtrsim 10$ lightcurves from $\gtrsim 2$ apparitions) of dense lightcurves smooths the shape models out, making them look more realistic, as confirmed by their better fit to occultation chords.

From observations of star occultations by asteroids, we can reconstruct asteroid projected silhouettes. These silhouettes can then be compared with the predicted contours of the convex shape models and used for the asteroid size determination by scaling the shape models to fit the occultation chords. A reasonable number of observations were available for three asteroids from our sample. By using the same methods as in Durech et al. (2011), we rejected mirror solutions for the asteroids (345) Tercidina and (578) Happelia, and also determined equivalent diameters (corresponding to spheres with the same volume as the scaled convex shape models): $96 \pm 10 \mathrm{~km}$ for

\footnotetext{
${ }^{10}$ Models based only on data from the Catalina Sky Survey are described later in Sect. 2.3.
}
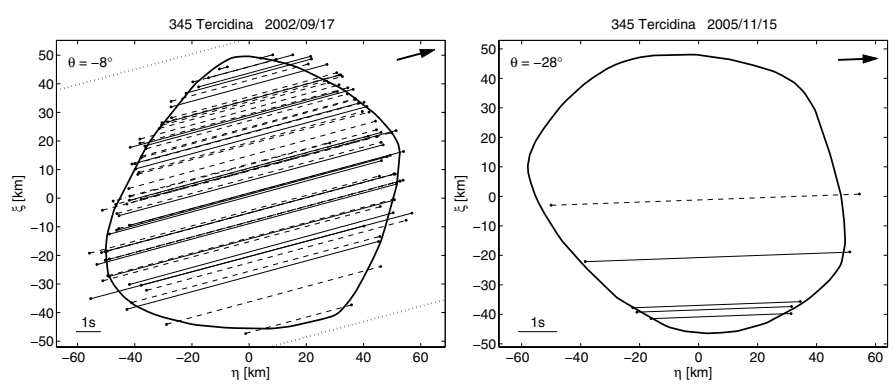

Fig. 1. Two observations of star occultations by asteroid (345) Tercidina. The solid contour corresponds to a scaled projected silhouette of the shape model with the pole $\left(346^{\circ},-55^{\circ}\right)$, each chord represents one occultation observation (solid lines are CCD, video, or photoelectric observations; dashed lines are visual observations, and dotted lines negative observations). Each plot also contains the time scale (lower left corner), the latitude of the sub-Earth point $\theta$ for the time of occultation (upper left corner), and the direction of the relative velocity (the arrow in the upper right corner). East points to the left and north up.
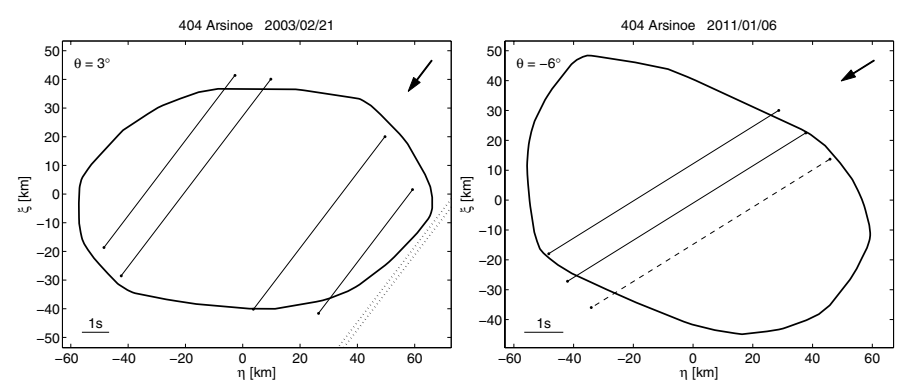

Fig. 2. Two observations of star occultations by asteroid (404) Arsinoe. The solid contour corresponds to a scaled projected silhouette of the shape model with the pole $\left(25^{\circ}, 57^{\circ}\right)$. See Fig. 1 for line types and symbols explanation.
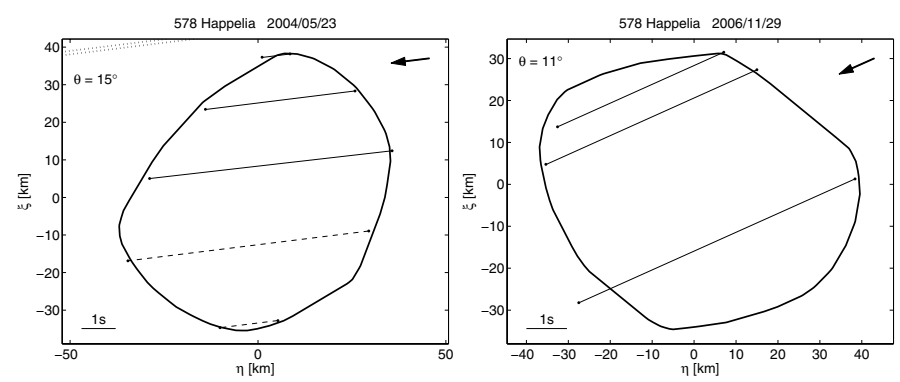

Fig. 3. Two observations of star occultations by asteroid (578) Happelia. The solid contour corresponds to a scaled projected silhouette of the shape model with the pole $\left(339^{\circ}, 62^{\circ}\right)$. See Fig. 1 for line types and symbols explanation.

(345) Tercidina, $101 \pm 5 \mathrm{~km}$ for (404) Arsinoe, and $70 \pm 5 \mathrm{~km}$ for (578) Happelia. Two different stellar occultations are available for all three asteroids, and are plotted in Figs. 1-3.

During the apparition in 2004, the lightcurves of asteroid (1089) Tama have shown features typical of close binary systems (Behrend et al. 2004) and indeed, the system was later interpreted as a synchronous close binary (Behrend et al. 2006). Our brick-like convex shape model is strongly elongated with sharp edges and is similar to a convex shape model of a close binary system (90) Antiope. Such a shape appearance for close binaries was predicted from synthetic data (Ďurech \& Kaasalainen 2003). 
Table 1. List of new asteroid models derived from combined dense and sparse data or from sparse data alone.

\begin{tabular}{|c|c|c|c|c|c|c|c|c|c|c|c|}
\hline & Asteroid & $\begin{array}{c}\lambda_{1} \\
\text { [deg] }\end{array}$ & $\begin{array}{c}\beta_{1} \\
\text { [deg] }\end{array}$ & $\begin{array}{c}\lambda_{2} \\
\text { [deg] }\end{array}$ & $\begin{array}{c}\beta_{2} \\
\text { [deg] }\end{array}$ & $\begin{array}{c}P \\
{[\mathrm{~h}]}\end{array}$ & $N_{\mathrm{lc}}$ & $N_{\text {app }}$ & $N_{689}$ & $N_{703}$ & $N_{950}$ \\
\hline 11 & Parthenope & 311 & 14 & 128 & 14 & 13.72205 & 107 & 13 & 297 & 24 & 147 \\
\hline 25 & Phocaea & 347 & 10 & & & 9.93540 & 22 & 5 & 272 & 100 & \\
\hline 72 & Feronia & 287 & -39 & 102 & -55 & 8.09068 & 20 & 5 & 196 & 124 & 127 \\
\hline 79 & Eurynome & 228 & 30 & 54 & 24 & 5.97772 & 36 & 4 & 240 & 168 & \\
\hline 147 & Protogeneia & 269 & 15 & 90 & 14 & 7.85232 & 11 & 3 & 152 & 80 & \\
\hline 149 & Medusa & 333 & -73 & 156 & -76 & 26.0454 & 13 & 4 & 134 & 60 & \\
\hline 157 & Dejanira & 319 & -64 & 146 & -33 & 15.8287 & 14 & 2 & 94 & 123 & \\
\hline 166 & Rhodope & 345 & -22 & 173 & -3 & 4.714793 & 7 & 2 & 141 & 111 & \\
\hline 178 & Belisana & 260 & 20 & 79 & 9 & 12.32139 & 35 & 3 & 147 & 127 & \\
\hline 183 & Istria & 85 & 20 & & & 11.76897 & 8 & 2 & 142 & 174 & \\
\hline 193 & Ambrosia & 141 & -11 & 328 & -17 & 6.58166 & 18 & 4 & 169 & 87 & \\
\hline 199 & Byblis & 344 & -24 & 165 & 9 & 5.22063 & 22 & 5 & 184 & 108 & \\
\hline 220 & Stephania & 26 & -50 & 223 & -62 & 18.2087 & 9 & 2 & 117 & 99 & \\
\hline 222 & Lucia & 106 & 50 & 293 & 49 & 7.83671 & 9 & 4 & 160 & 100 & \\
\hline 242 & Kriemhild & 100 & -40 & 285 & -15 & 4.545174 & 25 & 7 & 179 & 144 & \\
\hline 257 & Silesia & 5 & -53 & 176 & -46 & 15.7097 & 18 & 2 & 167 & 88 & \\
\hline 260 & Huberta & 23 & -28 & 206 & -19 & 8.29055 & 6 & 2 & 162 & 90 & \\
\hline 265 & Anna & 109 & -53 & & & 11.6903 & & & 114 & 79 & \\
\hline 272 & Antonia & 293 & -90 & & & 3.85480 & 7 & 2 & 109 & 92 & \\
\hline 281 & Lucretia & 128 & -49 & 309 & -61 & 4.349711 & 8 & 4 & 129 & 83 & \\
\hline 290 & Bruna & 286 & -80 & 37 & -74 & 13.8055 & 9 & 1 & 97 & 66 & \\
\hline 297 & Caecilia & 223 & -53 & 47 & -33 & 4.151388 & 15 & 5 & 149 & 130 & \\
\hline 345 & Tercidina & 346 & -55 & & & 12.37082 & 42 & 8 & 161 & 155 & \\
\hline 351 & Yrsa & 20 & -70 & 193 & -41 & 13.3120 & 2 & 1 & 183 & 52 & \\
\hline 352 & Gisela & 24 & -21 & 206 & -28 & 7.48008 & 6 & 4 & 134 & 140 & \\
\hline 371 & Bohemia & 93 & 49 & 256 & 43 & 10.73965 & 30 & 4 & 181 & 79 & \\
\hline 390 & Alma & 53 & -50 & 275 & -76 & 3.74117 & 5 & 2 & 142 & 58 & \\
\hline 403 & Cyane & 65 & 35 & 230 & 33 & 12.2700 & 7 & 3 & 186 & 104 & \\
\hline 404 & Arsinoe & 25 & 57 & & & 8.88766 & 49 & 9 & 199 & 104 & \\
\hline 406 & Erna & 357 & -49 & 161 & -60 & 8.79079 & 8 & 1 & 134 & 93 & \\
\hline 441 & Bathilde & 285 & 55 & 122 & 43 & 10.44313 & 32 & 7 & 158 & 112 & \\
\hline 507 & Laodica & 102 & -55 & 312 & -49 & 4.70657 & & & 162 & 103 & \\
\hline 509 & Iolanda & 245 & 65 & 98 & 38 & 12.2907 & 4 & 2 & 178 & 85 & \\
\hline 512 & Taurinensis & 324 & 45 & & & 5.58203 & 11 & 2 & 124 & 111 & \\
\hline 519 & Sylvania & 106 & 9 & 286 & -13 & 17.9647 & 5 & 2 & 147 & 76 & \\
\hline 528 & Rezia & 176 & -59 & 46 & -66 & 7.33797 & 6 & 2 & 151 & 77 & \\
\hline 531 & Zerlina & 78 & -84 & & & 16.7073 & 28 & 3 & 48 & 52 & \\
\hline 543 & Charlotte & 333 & 59 & 172 & 49 & 10.7184 & 4 & 1 & 138 & 98 & \\
\hline 572 & Rebekka & 1 & 54 & 158 & 39 & 5.65009 & 5 & 2 & 155 & 63 & \\
\hline 578 & Happelia & 339 & 62 & & & 10.06450 & 20 & 4 & 183 & 80 & \\
\hline 600 & Musa & 0 & -74 & 208 & -46 & 5.88638 & 23 & 7 & 96 & 132 & \\
\hline 669 & Kypria & 31 & 40 & 189 & 49 & 14.2789 & 5 & 1 & 142 & 126 & \\
\hline 708 & Raphaela & 37 & 27 & 217 & 22 & 20.8894 & 5 & 1 & 140 & 95 & \\
\hline 725 & Amanda & 145 & -63 & 320 & -70 & 3.74311 & 18 & 7 & 70 & 77 & \\
\hline 731 & Sorga & 83 & 40 & 275 & 21 & 8.18633 & 7 & 2 & 131 & 136 & \\
\hline 732 & Tjilaki & 160 & 23 & 353 & 24 & 12.3411 & 3 & 1 & 140 & 153 & \\
\hline 787 & Moskva & 331 & 59 & 126 & 27 & 6.05581 & 15 & 4 & 160 & 92 & \\
\hline 792 & Metcalfia & 88 & -14 & 274 & -13 & 9.17821 & 9 & 3 & 164 & 56 & \\
\hline 803 & Picka & 218 & 34 & 53 & 41 & 5.07478 & & & 154 & 50 & \\
\hline 807 & Ceraskia & 325 & 23 & 132 & 26 & 7.37390 & 2 & 1 & 132 & 111 & \\
\hline 812 & Adele & 301 & 44 & 154 & 69 & 5.85746 & & & 65 & 119 & \\
\hline 816 & Juliana & 124 & -8 & 304 & 10 & 10.5627 & 11 & 2 & 158 & 107 & \\
\hline 819 & Barnardiana & 169 & 46 & 334 & 47 & 66.698 & & & 121 & 86 & \\
\hline 852 & Wladilena & 181 & -48 & 46 & -53 & 4.613301 & 30 & 8 & 138 & 101 & \\
\hline 857 & Glasenappia & 227 & 48 & 38 & 34 & 8.20757 & 4 & 2 & 140 & 116 & \\
\hline 867 & Kovacia & 200 & -44 & 38 & -50 & 8.67807 & & & 78 & 76 & \\
\hline 874 & Rotraut & 201 & -41 & 2 & -36 & 14.3007 & 3 & 1 & 129 & 68 & \\
\hline 875 & Nymphe & 42 & 31 & 196 & 42 & 12.6213 & 6 & 1 & 94 & 100 & \\
\hline 900 & Rosalinde & 276 & 70 & 90 & 39 & 16.6868 & 3 & 2 & 125 & 170 & \\
\hline 920 & Rogeria & 238 & -15 & 47 & -35 & 12.5749 & & & 137 & 79 & \\
\hline
\end{tabular}

Notes. For each asteroid, the table gives the ecliptic coordinates $\lambda_{1}$ and $\beta_{1}$ of the pole solution with the lowest chi-square, the corresponding mirror solution $\lambda_{2}$ and $\beta_{2}$, the sidereal rotational period $P$, the number of dense lightcurves $N_{\text {lc }}$ observed during $N_{\text {app }}$ apparitions, and the number of sparse data points for the corresponding observatory: $N_{689}, N_{703}$ and $N_{950}$. The uncertainty of the sidereal rotational period corresponds to the last decimal place of $P$ and of the pole direction to $10-20^{\circ}$. 
J. Hanuš et al.: Asteroids' physical models

Table 1. continued.

\begin{tabular}{|c|c|c|c|c|c|c|c|c|c|c|c|}
\hline & Asteroid & $\begin{array}{c}\lambda_{1} \\
\text { [deg] }\end{array}$ & $\begin{array}{c}\beta_{1} \\
{[\mathrm{deg}]} \\
\end{array}$ & $\begin{array}{c}\lambda_{2} \\
{[\mathrm{deg}]}\end{array}$ & $\begin{array}{c}\beta_{2} \\
{[\mathrm{deg}]}\end{array}$ & $\begin{array}{c}P \\
{[\mathrm{~h}]}\end{array}$ & $N_{\mathrm{lc}}$ & $N_{\text {app }}$ & $N_{689}$ & $N_{703}$ & $N_{950}$ \\
\hline 958 & Asplinda & 41 & 48 & 226 & 35 & 25.3050 & 2 & 1 & 98 & 68 & \\
\hline 994 & Otthild & 183 & -50 & 41 & -39 & 5.94819 & 26 & 5 & 140 & 125 & \\
\hline 1040 & Klumpkea & 172 & 48 & & & 56.588 & & & 114 & 88 & \\
\hline 1056 & Azalea & 252 & 51 & 64 & 41 & 15.0276 & 3 & 1 & 122 & 112 & \\
\hline 1089 & Tama & 193 & 32 & 9 & 28 & 16.4461 & 90 & 7 & 108 & 79 & \\
\hline 1111 & Reinmuthia & 356 & 68 & 153 & 78 & 4.007347 & 13 & 3 & 137 & 65 & \\
\hline 1126 & Otero & 44 & 75 & 240 & 56 & 3.64800 & 2 & 1 & 101 & 110 & \\
\hline 1130 & Skuld & 24 & 36 & 200 & 35 & 4.80764 & 14 & 1 & 92 & 106 & \\
\hline 1188 & Gothlandia & 334 & -84 & & & 3.491820 & 36 & 5 & 134 & 91 & \\
\hline 1241 & Dysona & 125 & -68 & & & 8.60738 & 7 & 1 & 156 & 64 & \\
\hline 1249 & Rutherfordia & 32 & 74 & 197 & 65 & 18.2183 & 6 & 2 & 187 & 75 & \\
\hline 1317 & Silvretta & 45 & -57 & 161 & -46 & 7.06797 & 13 & 3 & 120 & 69 & \\
\hline 1386 & Storeria & 227 & -67 & 297 & -67 & 8.67795 & 10 & 1 & 33 & 78 & \\
\hline 1389 & Onnie & 183 & -75 & 0 & -79 & 23.0447 & 2 & 1 & 90 & 97 & \\
\hline 1393 & Sofala & 319 & 28 & 134 & 41 & 16.5931 & & & 69 & 91 & \\
\hline 1401 & Lavonne & 204 & 23 & 27 & 44 & 3.93261 & 3 & 1 & 109 & 88 & \\
\hline 1432 & Ethiopia & 41 & 44 & 225 & 54 & 9.84425 & 11 & 1 & 88 & 101 & \\
\hline 1436 & Salonta & 223 & 18 & 57 & 35 & 8.86985 & 10 & 2 & 132 & 90 & \\
\hline 1450 & Raimonda & 231 & -56 & 71 & -60 & 12.6344 & & & 74 & 116 & \\
\hline 1472 & Muonio & 249 & 61 & 42 & 62 & 8.70543 & 6 & 1 & 99 & 93 & \\
\hline 1490 & Limpopo & 319 & 22 & 142 & 2 & 6.65164 & 5 & 1 & 103 & 107 & \\
\hline 1495 & Helsinki & 355 & -39 & & & 5.33131 & 13 & 2 & 62 & 109 & \\
\hline 1518 & Rovaniemi & 62 & 60 & 265 & 45 & 5.25047 & 2 & 1 & 100 & 73 & \\
\hline 1528 & Conrada & 250 & -51 & 93 & -66 & 6.32154 & 2 & 1 & 93 & 126 & \\
\hline 1554 & Yugoslavia & 281 & -34 & 78 & -64 & 3.88766 & 3 & 1 & 75 & 75 & \\
\hline 1559 & Kustaanheimo & 275 & 29 & 94 & 33 & 4.30435 & & & 53 & 82 & \\
\hline 1572 & Posnania & 205 & -82 & 85 & -63 & 8.04945 & 46 & 7 & 141 & 83 & \\
\hline 1607 & Mavis & 0 & 59 & 222 & 70 & 6.14775 & 4 & 1 & 141 & 179 & \\
\hline 1630 & Milet & 304 & 34 & 121 & 40 & 32.485 & 3 & 1 & 72 & 92 & \\
\hline 1634 & Ndola & 261 & 45 & 66 & 34 & 64.255 & 7 & 1 & 71 & 110 & \\
\hline 1704 & Wachmann & 267 & 41 & 90 & 40 & 3.31391 & & & 54 & 135 & \\
\hline 1715 & Salli & 95 & -24 & 254 & -48 & 11.08867 & 2 & 1 & 84 & 97 & \\
\hline 1719 & Jens & 286 & -88 & 55 & -42 & 5.87016 & 4 & 2 & 78 & 53 & \\
\hline 1785 & Wurm & 11 & 57 & 192 & 47 & 3.26934 & 2 & 1 & 43 & 115 & \\
\hline 1837 & Osita & 167 & -64 & 352 & -54 & 3.81879 & & & 82 & 62 & \\
\hline 1905 & Ambartsumian & 52 & -64 & 241 & -68 & 92.153 & & & 50 & 101 & \\
\hline 1927 & Suvanto & 74 & 73 & 278 & 23 & 8.16154 & 4 & 1 & 64 & 119 & \\
\hline 1933 & Tinchen & 113 & 26 & 309 & 36 & 3.67062 & & & 72 & 103 & \\
\hline 1950 & Wempe & 90 & -41 & 258 & -45 & 16.7953 & 1 & 1 & 96 & 46 & \\
\hline 1963 & Bezovec & 219 & 7 & & & 18.1655 & 12 & 2 & 103 & 40 & \\
\hline 1996 & Adams & 107 & 55 & & & 3.31114 & & & 82 & 120 & \\
\hline 2002 & Euler & 30 & 44 & 188 & 47 & 5.99264 & 7 & 2 & & 85 & \\
\hline 2094 & Magnitka & 107 & 57 & 272 & 48 & 6.11219 & & & 25 & 84 & \\
\hline 2510 & Shandong & 256 & 27 & 71 & 27 & 5.94639 & 4 & 1 & & 132 & \\
\hline 2606 & Odessa & 25 & -81 & 283 & -88 & 8.2444 & 3 & 1 & 25 & 129 & \\
\hline 2709 & Sagan & 302 & -14 & 124 & -35 & 5.25636 & 6 & 2 & & 160 & \\
\hline 2839 & Annette & 341 & -49 & 154 & -36 & 10.4609 & 8 & 1 & & 99 & \\
\hline 2957 & Tatsuo & 81 & 45 & 248 & 32 & 6.82043 & 13 & 1 & 33 & 102 & \\
\hline 2991 & Bilbo & 277 & 54 & 90 & 51 & 4.06175 & 3 & 1 & & 97 & \\
\hline 3722 & Urata & 260 & -22 & 77 & -9 & 5.5671 & 10 & 3 & & 70 & \\
\hline 4954 & Eric & 86 & -54 & & & 12.05207 & 7 & 2 & & 68 & \\
\hline 5281 & Lindstrom & 238 & -72 & 84 & -81 & 9.2511 & 2 & 1 & & 76 & \\
\hline 7517 & 1989 AD & 314 & -60 & 123 & -51 & 9.7094 & 4 & 1 & & 81 & \\
\hline 8132 & Vitginzburg & 33 & -66 & 193 & -48 & 7.27529 & 3 & 1 & & 100 & \\
\hline 8359 & 1989 WD & 121 & -68 & 274 & -68 & 2.89103 & 6 & 1 & & 105 & \\
\hline 10772 & $1990 \mathrm{YM}$ & 16 & 46 & & & 68.82 & 5 & 1 & & 73 & \\
\hline 31383 & $1998 \mathrm{XJ}_{94}$ & 110 & -74 & 279 & -63 & 4.16818 & 4 & 1 & & 71 & \\
\hline 52820 & $1998 \mathrm{RS}_{2}$ & 228 & -57 & 58 & -48 & 2.13412 & 1 & 1 & & 45 & \\
\hline 57394 & $2001 \mathrm{RD}_{84}$ & 65 & 68 & 241 & 59 & 6.7199 & 4 & 1 & & 47 & \\
\hline
\end{tabular}


A\&A 551, A67 (2013)

Table 2. List of new asteroid models derived from the Catalina Sky Survey data alone.

\begin{tabular}{|c|c|c|c|c|c|c|c|c|c|}
\hline & Asteroid & $\begin{array}{c}\lambda_{1} \\
{[\mathrm{deg}]}\end{array}$ & $\begin{array}{c}\beta_{1} \\
{[\mathrm{deg}]}\end{array}$ & $\begin{array}{c}\lambda_{2} \\
{[\mathrm{deg}]}\end{array}$ & $\begin{array}{c}\beta_{2} \\
{[\mathrm{deg}]}\end{array}$ & $\begin{array}{c}P \\
{[\mathrm{~h}]}\end{array}$ & $N_{703}$ & $\begin{array}{c}P_{\text {publ }} \\
{[\mathrm{h}]}\end{array}$ & Period reference \\
\hline 2112 & Ulyanov & 156 & 48 & 334 & 65 & 3.04071 & 118 & 3.000 & Maleszewski \& Clark (2004) \\
\hline 2384 & Schulhof & 196 & -60 & 45 & -42 & 3.29367 & 121 & 3.294 & Ditteon et al. (2002) \\
\hline 2617 & Jiangxi & 224 & 76 & 1 & 54 & 11.7730 & 124 & 11.79 & Carbo et al. (2009) \\
\hline 3170 & Dzhanibekov & 217 & 60 & 21 & 64 & 6.07168 & 105 & 6.0724 & Molnar et al. (2008) \\
\hline 4507 & $1990 \mathrm{FV}$ & 143 & 55 & 323 & 49 & 6.57933 & 84 & 6.58 & Yoshida et al. (2005) \\
\hline 5647 & $1990 \mathrm{TZ}$ & 253 & 77 & 119 & -19 & 6.13867 & 87 & 6.144 & Bembrick \& Bolt (2003) \\
\hline 10826 & $1993 \mathrm{SK}_{16}$ & 260 & -56 & 60 & -34 & 13.8327 & 90 & 13.835 & Galad (2008) \\
\hline 19848 & Yeungchuchiu & 190 & -68 & & & 3.45104 & 104 & 3.450 & Yeung (2006) \\
\hline 3097 & Tacitus & 229 & 71 & 72 & 62 & 8.7759 & 99 & & \\
\hline 4611 & Vulkaneifel & 5 & -86 & 197 & -50 & 3.75635 & 148 & & \\
\hline 5461 & Autumn & 249 & -26 & 79 & -43 & 20.0929 & 106 & & \\
\hline 5625 & $1991 \mathrm{AO}_{2}$ & 265 & -52 & 97 & -78 & 6.67411 & 110 & & \\
\hline 5960 & Wakkanai & 226 & -69 & 69 & -61 & 4.96286 & 102 & & \\
\hline 7201 & Kuritariku & 22 & 67 & 249 & 64 & 48.849 & 103 & & \\
\hline 7632 & Stanislav & 234 & -50 & 46 & -45 & 5.29073 & 99 & & \\
\hline 7905 & Juzoitami & 105 & -76 & 226 & -55 & 2.72744 & 118 & & \\
\hline 13002 & $1982 \mathrm{BJ}_{13}$ & 58 & -50 & 245 & -57 & 3.13844 & 110 & & \\
\hline 16009 & $1999 \mathrm{CM}_{8}$ & 283 & 44 & & & 8.3476 & 124 & & \\
\hline 16847 & Sanpoloamosciano & 91 & -24 & & & 8.1845 & 114 & & \\
\hline 26792 & 1975 LY & 226 & 68 & & & 79.15 & 140 & & \\
\hline
\end{tabular}

Notes. For each asteroid, the table gives the ecliptic coordinates $\lambda_{1}$ and $\beta_{1}$ of the pole solution, the corresponding mirror solution $\lambda_{2}$ and $\beta_{2}$, the sidereal rotational period $P$, the number of sparse data points from the CSS $N_{703}$, and the previously published period value $P_{\text {publ }}$ with the reference. The uncertainty of the sidereal rotational period corresponds to the last decimal place of $P$ and of the pole direction to $20-40^{\circ}$.

\subsection{Models based on data from the Catalina Sky Survey astrometric project}

There are two different groups of asteroid models based on CSS data: (i) models with previously reported synodic periods determined from dense data (we did not have these dense data, so period values were taken from the literature, usually from the Minor Planet Lightcurve Database); and (ii) models with previously unknown rotational periods. In the first case, we could compare the published period value with the period value derived by the LI (see Table 2, Cols. 7 and 9). If both periods agreed within their uncertainties, we considered the solution reliable. This test could not be performed for the second group of models, so we had to use additional reliability tests (see Sect. 2.1).

In Table 2, we present 20 asteroid models based only on the CSS data. The previous period estimates were not available for 12 of them. All of these 20 models have higher uncertainties of the pole orientations and lower shape resolution than models based on combined data, and all are possible candidates for follow-up lightcurve observations for period confirmation and more detailed shape determination.

\section{Semi-empirical scaling of the YORP effect}

Our enlarged sample of physical parameters for $\sim 330$ asteroids $^{11}$ validates our previous results based on a smaller asteroid sample (220 asteroids) presented in Hanuš et al. (2011). In Fig. 4, we show the observed debiased (i.e., we removed the systematic effect of the lightcurve inversion method caused by the method having a higher probability of deriving a unique solution for asteroids with larger pole latitudes. The debiasing procedure was based on a numerical simulation presented in Hanuš et al. 2011,

\footnotetext{
${ }_{11}$ According to the asteroid size distribution function of Davis et al. (2002), we have in our sample $\sim 30 \%$ of all asteroids with $D>100 \mathrm{~km}$, $\sim 15 \%$ asteroids with $60 \mathrm{~km}<D<100 \mathrm{~km}$, and $\sim 14 \%$ asteroids with $30 \mathrm{~km}<D<60 \mathrm{~km}$.
}
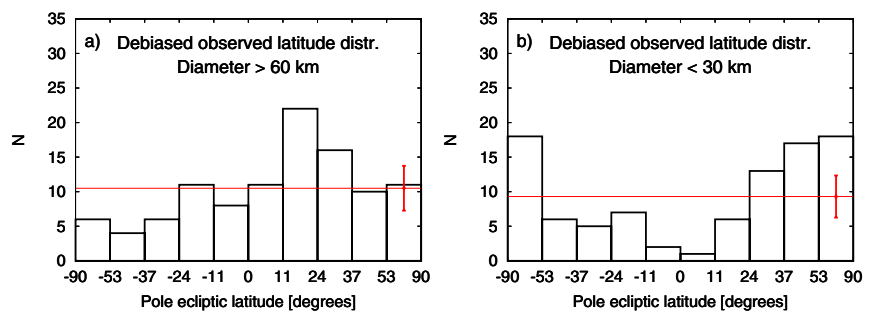

Fig. 4. Debiased observed latitude distribution of main-belt asteroids with diameters $D>60 \mathrm{~km}$ (left panel) and $D<30 \mathrm{~km}$ (right panel). The latitude bins are equidistant in $\sin \beta$. The thin horizontal line corresponds to the average value $\bar{N}$ and the errorbar to $\sqrt{\bar{N}}$.

see Sect. 4.3 there) latitude distributions of pole directions for main-belt asteroids with diameters $D<30 \mathrm{~km}$ and $D>60 \mathrm{~km}$. The population of larger asteroids $(D>60 \mathrm{~km})$ exhibits an excess of prograde rotators, probably of primordial origin (predicted also from numerical simulations by Johansen \& Lacerda 2010). On the other hand, smaller asteroids $(D<30 \mathrm{~km})$ have a clearly bimodal latitude distribution - most of the asteroids have ecliptic pole latitudes $>53^{\circ}$.

The debiased observed latitude distribution of the pole directions of MBAs represents fingerprints from the past evolution of this population. Direct comparison between the observed asteroid properties and predictions of theoretical models can validate/exclude some of the asteroid dynamical evolution theories or constrain specific free parameters.

In Hanuš et al. (2011), we introduced a simple dynamical model for the spin evolution of asteroids, where we included (i) the YORP thermal effect; (ii) random reorientations induced by noncatastrophic collisions; (iii) oscillations caused by gravitational torques and spin-orbital resonances; and also (iv) mass shedding when a critical rotational frequency is reached. Because we studied a large statistical sample of 
asteroids, the effect on the overall latitude distribution of pole directions caused by other processes (gravitational torques by the Sun, damping, or tumbling) was assumed to be only minor.

The model was based on the relations for the rate of the angular velocity $\omega(\omega=2 \pi / P)$ and the obliquity $\epsilon$ (Euler equations)

$$
\begin{aligned}
\frac{\mathrm{d} \omega}{\mathrm{d} t} & =c f_{i}(\epsilon), \quad i=1 \ldots 200, \\
\frac{\mathrm{d} \epsilon}{\mathrm{d} t} & =\frac{c g_{i}(\epsilon)}{\omega},
\end{aligned}
$$

where $f$ - and $g$-functions describing the YORP effect for a set of 200 shapes with the effective radius $R_{0}=1 \mathrm{~km}$, the bulk density $\rho_{0}=2500 \mathrm{~kg} / \mathrm{m}^{3}$, located on a circular orbit with the semimajor axis $a_{0}=2.5 \mathrm{AU}$, were calculated numerically by Čapek \& Vokrouhlický (2004). We assigned one of the artificial shapes (denoted by the index $i$ ) for each individual asteroid from our sample ${ }^{12}$. The $f$ - and $g$-functions were scaled by a factor

$c=c_{\text {YORP }}\left(\frac{a}{a_{0}}\right)^{-2}\left(\frac{R}{R_{0}}\right)^{-2}\left(\frac{\rho_{\text {bulk }}}{\rho_{0}}\right)^{-1}$,

where $a, R, \rho_{\text {bulk }}$ denote the semi-major axis, the radius, and the density of the simulated body, respectively, and $c_{\text {YORP }}$ is a free scaling parameter reflecting our uncertainty in the shape models and the magnitude of the YORP torque, which dependents on small-sized surface features (even boulders, Statler 2009) and other simplifications in the modeling of the YORP torque.

We enhanced the simulation of the spin evolution of asteroids presented in Hanuš et al. (2011), by testing different values of the free parameter $c_{\text {YORP }}$ and comparing the resulting synthetic latitude distributions with the observed debiased latitude distributions. Thanks to the new asteroid models, we had an updated observed spin vector distribution. We added $50 \%$ more observed asteroids, so we used 307 instead of 220 models for this comparison.

We used the following values of the parameter $c_{\text {YORP: }} 0.01$, $0.05,0.1,0.2,0.3,0.4,0.5,0.6,0.8$. Values of $c_{\text {YORP }} \gtrsim 1$ were already recognized as unrealistic.

For each value of $c_{\text {YORP, }}$, we ran 100 simulations with different random seeds to generate different initial $\omega$ and spin vector distributions. We integrated Eqs. (1) and (2) numerically. The time span was 4 Gyr with the time step of the explicit Euler scheme $\Delta t=10 \mathrm{Myr}$. As initial conditions, we assumed a Maxwellian distribution of angular velocities $\omega$ and isotropically distributed spin vectors. We also used $K=10^{-2} \mathrm{~W} / \mathrm{K} / \mathrm{m}$, $\rho_{\text {bulk }}=2500 \mathrm{~kg} / \mathrm{m}^{3}$.

Every time a critical angular velocity $\left(\omega_{\text {crit }}=\sqrt{4 / 3 \pi G \rho_{\text {bulk }}}\right)$ was reached for an asteroid, we assumed a mass shedding event, so that we reset the rotational period to a random value from an interval of $2.5,9 \mathrm{~h}$. We altered the assigned shape, but we kept the sense of the rotation and the orientation of the spin axis. We also included a simple Monte-Carlo model for the spin axis reorientations caused by collisions (with $\tau_{\text {reor }}=B\left(\frac{\omega}{\omega_{0}}\right)^{\beta_{1}}\left(\frac{D}{D_{0}}\right)^{\beta_{2}}$, where $B=84.5 \mathrm{kyr}, \beta_{1}=5 / 6, \beta_{2}=4 / 3, D_{0}=2 \mathrm{~m}$, and $\omega_{0}$ corresponds to period $P=5 \mathrm{~h}$, Farinella et al. 1998). After the collision, we reset the spin axis and period to random values (new period was from an interval of $2.5,9 \mathrm{~h}$ ). Collisional disruptions are not important in our case so they were not considered.

\footnotetext{
${ }^{12}$ We did not use the convex-hull shape models derived in this work because the two samples of shapes are believed to be statistically equivalent, and moreover, the YORP effect seems sensitive to small-scale surface structure (Scheeres \& Mirrahimi 2007), which cannot be caught by our shape models.
}

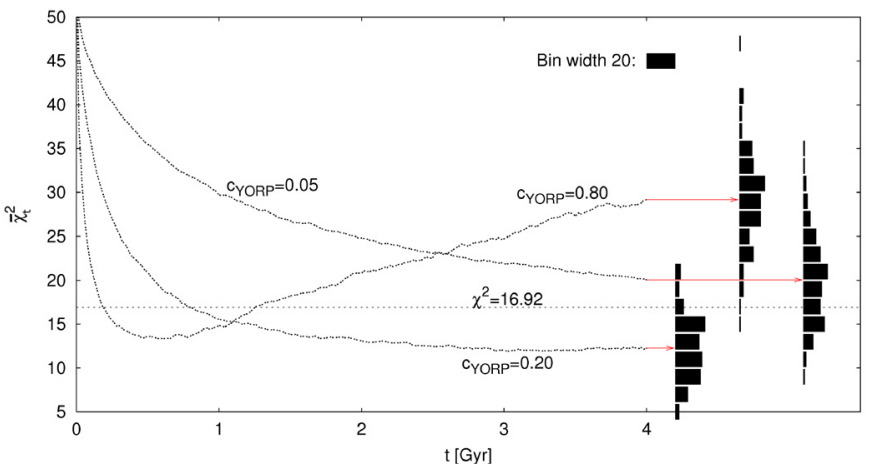

Fig. 5. Temporal evolution of the $\chi^{2}$ that corresponds to the difference between the simulated latitude distributions, averaged over all 100 runs, and the debiased observed latitude distribution (i.e., $\bar{\chi}_{t}^{2}$ ) for three different values of parameter $c_{\text {YORP }}=0.05,0.20$, and 0.80 (we performed a chi-square test). Vertical histograms on the righthand side represent the distributions of $\chi_{t j}^{2}$ at time $t=4 \mathrm{~Gy}$ for all 100 runs. Dotted line: the statistically significant probability value of $5 \%$, i.e. $\chi^{2}=16.92$.

We also accounted for spin-orbital resonances by adding a sinusoidal oscillation to $\beta$ (to prograde rotators, only, Vokrouhlický et al. 2006b) with a random phase and an amplitude $\simeq 40^{\circ}$.

The spin states of our synthetic asteroids evolve during the simulation. At each time $t$ of the simulation, we can construct a latitude distribution of the pole directions with the latitude values split into ten bins with a variable width corresponding to constant surface on the celestial sphere. Because we used ecliptic coordinates with the longitude $\lambda$ and the latitude $\beta$, the bins were equidistant in $\sin \beta$. To describe the temporal evolution of the simulated latitude distributions, we computed a $\chi^{2}$ metric between the simulated and the debiased observed latitude distributions of asteroids with diameters $D<60 \mathrm{~km}$. The assumption of isotropically distributed initial spin vectors is not fulfilled for larger asteroids $(D>60 \mathrm{~km})$, because this population has an excess of prograde rotators (see Fig. 4), which is believed to have a primordial origin (Johansen \& Lacerda 2010). The second reason we rejected asteroids with $D>60 \mathrm{~km}$ from latitude comparison is that their evolution is rather slow compared to the simulation time span.

For each time $t$ within the simulation run $j(j=1 \ldots 100)$, the corresponding chi-square value $\chi_{t j}^{2}$ is defined by

$\chi_{t j}^{2} \equiv \sum_{i} \frac{\left(S_{t j i}-O_{i}\right)^{2}}{\sigma_{t j i}^{2}}$,

where $S_{t j i}$ denotes the number of synthetic bodies with latitudes in bin $i, O_{i}$ the number of observed latitudes in bin $i$, and $\sigma_{t j i} \equiv$ $\sqrt{S_{t j i}+O_{i}}$ corresponds to the uncertainty estimate.

In Fig. 5, we show the temporal evolution of the average chi-square $\bar{\chi}_{t}^{2}=\sum_{j} \chi_{t j}^{2} / 100$ in the course of our numerical sim-

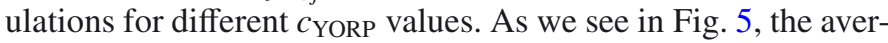
age synthetic latitude distribution evolves in course of the time (while the debiased observed latitude distribution is fixed). We can distinguish three basic cases of the temporal evolution:

- When the YORP effect is weak ( $c_{\text {YORP }} \lesssim 0.1$ ), the synthetic latitude distribution only evolves slowly and is never similar to the observed latitude distribution, even at the end of the simulation, because $\bar{\chi}_{t}^{2}$ is still large (for $N=9$, a statistically significant probability value of $5 \%$ corresponds to $\left.\chi^{2}=16.92\right)$. 


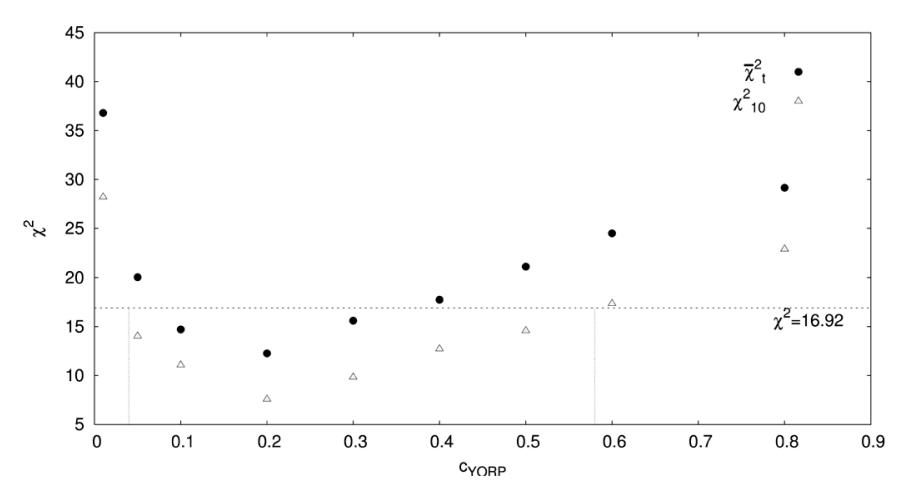

Fig. 6. Dependence of $\bar{\chi}_{t}^{2}$ and $\chi_{10}^{2}$ values calculated for the time $t=$ $4 \mathrm{Gyr}$ (i.e. the final state of the simulation) on different values of the $c_{\text {YORP }}$ parameter. We also plotted the statistically significant probability value of $5 \%$ which corresponds to $\chi^{2}=16.92$ and the interval of plausible $c_{\text {YORP }}$ values from 0.05 to 0.6 .

- A steady state (i.e., the state when the synthetic latitude distribution does not significantly evolve in time, and thus the $\bar{\chi}_{t}^{2}$ is approximately constant) is only reached for $c_{\text {YORP }}$ values close to 0.2 .

- For values $c_{\text {YORP }} \gtrsim 0.3$, the synthetic latitude distribution evolves faster and, at a certain time, is most similar to the observed latitude distribution (i.e., the minimum of $\bar{\chi}_{t}^{2}$ ). After that, the $\bar{\chi}_{t}^{2}$ grows, because the YORP significantly develops also larger asteroids, and thus the bins with low latitudes are depopulated more than is observed.

Vertical histograms on the righthand side of Fig. 5 represent the distributions of $\chi_{t j}^{2}$ at the time $t=4$ Gy for all 100 runs. The average chi-square $\bar{\chi}_{t}^{2}$ of the model with $c_{\text {YORP }}=0.05$ is substantially higher than 16.92 , so this model can be considered wrong. However, from the distributions of $\chi_{t j}^{2}$ we can see that about $25 \%$ of individual runs have $\chi_{t j}^{2}$ lower than 16.92. To avoid rejecting those $c_{\text {YORP }}$ values that are partially compatible with the observations, we should instead use a more representative value of $\chi^{2}$ than the average $\bar{\chi}_{t}^{2}$, namely a value $\chi_{10}^{2}$, for which $10 \%$ runs have lower $\chi_{t j}^{2}$ (see Fig. 6). Based on the $\chi_{10}^{2}$, the most probable values of the $c_{\text {YORP }}$ parameter are between 0.05 and 0.6 .

\section{Discusion and conclusions}

Our preferred interpretation of the optimal $c_{\text {YORP }}$ value being much lower than one is that small-scale features (boulders) tend to decrease the YORP torque. This hypothesis is supported by the independent modeling of Rozitis \& Green (2012), who estimate, by including rough surface thermal-infrared beaming effects in their long-term spin evolution model, that the surface roughness is on average responsible for damping the magnitude of the YORP effect typically by half of the smooth surface predictions. This would correspond to $c_{\text {YORP }}=0.5$ in our notation. The YORP effect is sensitive to the sizes of the boulders and can vary tens of percent, so the results of Rozitis \& Green (2012) agree with our model.

As an important application, we mention that the constraint for the value of $c_{\text {YORP }}$ can be used in simulations of the longterm dynamical evolution of asteroid families. So far, $c_{\text {YORP }}$ has been used as a free parameter (e.g., in the method presented by Vokrouhlický et al. 2006a). Constraining $c_{\text {YORP }}$ therefore $r e-$ moves one free parameter from the simulations and should thus lead to a better determination of the ages of asteroid families.
Finally, the results of this paper can be briefly summarized as follows.

- For 119 asteroids, we derived the convex shape models and rotational states from their combined disk-integrated dense and sparse photometric data. This effort was achieved with the help of $\sim 100$ individual observers who were willing to share their lightcurves. The typical uncertainty of the sidereal rotational period is $\sim 10^{-5} \mathrm{~h}$ and of the pole direction 10-20 $0^{\circ}$ All new models are now included in the DAMIT database.

- We also derived 20 asteroid models based purely on sparse-in-time photometry from the Catalina Sky Survey Observatory. The reliability of these models is supported by the fact that for eight of them, we obtained similar rotational period values that were previously reported in the literature and derived from an independent data set (dense photometry). We do not have any previous information about the rotational periods for the 12 other asteroids. Due to relatively larger uncertainties of the CSS sparse data, the typical uncertainty of the sidereal rotational period is $\sim 10^{-4}-10^{-5} \mathrm{~h}$ and of the pole direction $20-40^{\circ}$.

- By combining observations of stellar occultations by asteroids with derived convex shape models, we determined equivalent diameters for the asteroids (345) Tercidina, (404) Arcinoe, and (578) Happelia to $96 \pm 10 \mathrm{~km}$, $101 \pm 5 \mathrm{~km}$, and $70 \pm 5 \mathrm{~km}$, respectively.

- We updated a simple dynamical model for the spin evolution of asteroids and compared the synthetic pole latitude distributions to the debiased observed latitude distributions of 307 asteroids. By using several values of the scaling pa-

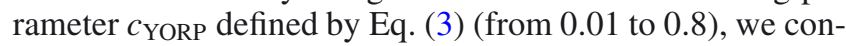
strained its value to $c_{\text {YORP }} \in[0.05,0.6]$. We interpreted the low value of $c_{\text {YORP }}$ as a result of the surface roughness.

Acknowledgements. The work of JH has been supported by grant GA UK 134710 of the Grant agency of the Charles University and by the project SVV 265301 of the Charles University in Prague. The work of J.H. and J.D. has been supported by grants GACR 209/10/0537 and P209/12/0229 of the Czech Science Foundation, the work of J.D. and M.B. by the Research Program MSM0021620860 of the Czech Ministry of Education, and the work of MB also by the grant GACR 13-01308S of the Grant Agency of the Czech Republic. The work of TSR was carried out through the Gaia Research for European Astronomy Training (GREAT-ITN) network. He has received funding from the European Union Seventh Framework Program (FP7/2007-2013) under grant agreement no. 264895. This work is partially based on observations made at the South African Astronomical Observatory (SAAO). It was based on observations made with the Nordic Optical Telescope, operated on the island of La Palma jointly by Denmark, Finland, Iceland, Norway, and Sweden, in the Spanish Observatorio del Roque de los Muchachos of the Instituto de Astrofisica de Canarias. This work is partially based on observations carried out with the Pic du Midi Observatory $0.6 \mathrm{~m}$ telescope, a facility operated by the Observatoire MidiPyrénées and Association T60, an amateur association. The calculations were performed on the computational cluster Tiger at the Astronomical Institute of Charles University in Prague (http://sirrah.troja.mff.cuni.cz/tiger).

\section{References}

Baker, R. E., Pilcher, F., \& Klinglesmith III, D. A. 2012, Minor Planet Bulletin, 39,60

Behrend, R., Roy, R., Rinner, C., et al. 2004, IAU Circ., 8265, 2

Behrend, R., Bernasconi, L., Roy, R., et al. 2006, A\&A, 446, 1177

Bembrick, C., \& Bolt, G. 2003, Minor Planet Bulletin, 30, 42

Bembrick, C., Crawford, G., Oey, J., \& Allen, B. 2007, Minor Planet Bulletin, 34, 67

Brinsfield, J. W. 2008a, Minor Planet Bulletin, 35, 179

Brinsfield, J. W. 2008b, Minor Planet Bulletin, 35, 86

Brinsfield, J. W. 2009, Minor Planet Bulletin, 36, 169

Buchheim, R. K. 2005, Minor Planet Bulletin, 32, 35

Buchheim, R. K. 2007, Minor Planet Bulletin, 34, 68 
Buchheim, R. K. 2010, Minor Planet Bulletin, 37, 41

Buchheim, R. K., Conjat, M., Roy, R., Baudoin, P., \& Behrend, R. 2004, Minor Planet Bulletin, 31, 90

Čapek, D., \& Vokrouhlický, D. 2004, Icarus, 172, 526

Carbo, L., Kragh, K., Krotz, J., et al. 2009, Minor Planet Bulletin, 36, 91

Davis, D. R., Durda, D. D., Marzari, F., Campo Bagatin, A., \& Gil-Hutton, R. 2002, Asteroids III, 545

Ditteon, R., Bixby, A. R., Sarros, A. M., \& Waters, C. T. 2002, Minor Planet Bulletin, 29, 69

Ďurech, J., \& Kaasalainen, M. 2003, A\&A, 404, 709

Durech, J., Scheirich, P., Kaasalainen, M., et al. 2007, in IAU Symp., 236, eds. G. B. Valsecchi, D. Vokrouhlický, \& A. Milani, 191

Ďurech, J., Kaasalainen, M., Warner, B. D., et al. 2009, A\&A, 493, 291

Durech, J., Sidorin, V., \& Kaasalainen, M. 2010, A\&A, 513, A46

Durech, J., Kaasalainen, M., Herald, D., et al. 2011, Icarus, 214, 652

Farinella, P., Vokrouhlicky, D., \& Hartmann, W. K. 1998, Icarus, 132, 378

Galad, A. 2008, Minor Planet Bulletin, 35, 128

Hanuš, J., \& Ďurech, J. 2012, Planet. Space Sci., 73, 75

Hanuš, J., Ďurech, J., Brož, M., et al. 2011, A\&A, 530, A134

Higgins, D. 2008, Minor Planet Bulletin, 35, 30

Higgins, D., \& Goncalves, R. M. D. 2007, Minor Planet Bulletin, 34, 16

Higgins, D., \& Warner, B. D. 2009, Minor Planet Bulletin, 36, 159

Higgins, D., Pravec, P., Kusnirak, P., et al. 2006, Minor Planet Bulletin, 33, 89

Higgins, D., Pravec, P., Kusnirak, P., et al. 2008, Minor Planet Bulletin, 35, 123

Johansen, A., \& Lacerda, P. 2010, MNRAS, 404, 475

Kaasalainen, M., \& Torppa, J. 2001, Icarus, 153, 24

Kaasalainen, M., Torppa, J., \& Muinonen, K. 2001, Icarus, 153, 37

Kaasalainen, M., Torppa, J, \& Piironen, J. 2002, Icarus, 159, 369

Koff, R. A., \& Brincat, S. M. 2000, Minor Planet Bulletin, 27, 49

Kryszczyńska, A., La Spina, A., Paolicchi, P., et al. 2007, Icarus, 192, 223

Lagerkvist, C., Barucci, M. A., Capria, M. T., et al. 1987, Asteroid photometric catalogue, eds. C.-I. Lagerkvist, M. A. Barucci, M. T. Capria, et al.

Larson, S., Beshore, E., Hill, R., et al. 2003, in BAAS, 35, AAS/Division for Planetary Sciences Meeting Abstracts \#35, 982

López-González, M. J., \& Rodríguez, E. 2000, A\&AS, 145, 255

Maleszewski, C., \& Clark, M. 2004, Minor Planet Bulletin, 31, 93

Marciniak, A., Michałowski, T., Kaasalainen, M., et al. 2007, A\&A, 473, 633

Marciniak, A., Michałowski, T., Kaasalainen, M., et al. 2008, A\&A, 478, 559

Michałowski, T. 1996, Icarus, 123, 456

Michałowski, T., Pych, W., Kwiatkowski, T., et al. 2001, A\&A, 371, 748

Michałowski, T., Kwiatkowski, T., Kaasalainen, M., et al. 2004, A\&A, 416, 353

Molnar, L. A., Haegert, J. M., Beaumont, C. N., et al. 2008, Minor Planet Bulletin, 35, 9

Oey, J. 2008, Minor Planet Bulletin, 35, 132

Oey, J. 2009, Minor Planet Bulletin, 36, 4

Oey, J., \& Krajewski, R. 2008, Minor Planet Bulletin, 35, 47

Oey, J., Behrend, R., Pravec, P., et al. 2007, Minor Planet Bulletin, 34, 2

Piironen, J., Lagerkvist, C., Torppa, J., Kaasalainen, M., \& Warner, B. 2001, in BAAS, 33, 1562

Pilcher, F. 2008, Minor Planet Bulletin, 35, 135

Pilcher, F. 2009a, Minor Planet Bulletin, 36, 133

Pilcher, F. 2009b, Minor Planet Bulletin, 36, 25

Pilcher, F. 2009c, Minor Planet Bulletin, 36, 100

Pilcher, F. 2010, Minor Planet Bulletin, 37, 119

Pilcher, F. 2011a, Minor Planet Bulletin, 38, 183

Pilcher, F. 2011b, Minor Planet Bulletin, 38, 76

Pilcher, F., \& Brinsfield, J. W. 2011, Minor Planet Bulletin, 38, 206

Pilcher, F., Benishek, V., \& Oey, J. 2009, Minor Planet Bulletin, 36, 68

Polishook, D. 2012, Minor Planet Bulletin, 39, 242

Polishook, D., \& Brosch, N. 2008, Icarus, 194, 111

Polishook, D., \& Brosch, N. 2009, Icarus, 199, 319

Polishook, D., Ofek, E. O., Waszczak, A., et al. 2012, MNRAS, 421, 2094

Pravec, P., Scheirich, P., Vokrouhlický, D., et al. 2012, Icarus, 218, 125

Rau, A., Kulkarni, S. R., Law, N. M., et al. 2009, PASP, 121, 1334

Rozitis, B., \& Green, S. F. 2012, MNRAS, 423, 367

Rubincam, D. P. 2000, Icarus, 148, 2

Ruthroff, J. C. 2010, Minor Planet Bulletin, 37, 102

Scheeres, D. J., \& Mirrahimi, S. 2007, in BAAS, 38, 416

Statler, T. S. 2009, Icarus, 202, 502

Stephens, R. D. 2005a, Minor Planet Bulletin, 32, 82

Stephens, R. D. 2005b, Minor Planet Bulletin, 32, 2

Stephens, R. D. 2008, Minor Planet Bulletin, 35, 126

Stephens, R. D. 2009a, Minor Planet Bulletin, 36, 59

Stephens, R. D. 2009b, Minor Planet Bulletin, 36, 18

Svoren, J., Husarik, M., Ambroz, J., Drbohlav, J., \& Medek, J. 2009, Earth Moon and Planets, 105, 361

Vokrouhlický, D., Brož, M., Morbidelli, A., et al. 2006a, Icarus, 182, 92

Vokrouhlický, D., Nesvorný, D., \& Bottke, W. F. 2003, Nature, 425, 147
Vokrouhlický, D., Nesvorný, D., \& Bottke, W. F. 2006b, Icarus, 184, 1

Warner, B. D. 2004, Minor Planet Bulletin, 31, 85

Warner, B. D. 2005a, Minor Planet Bulletin, 32, 90

Warner, B. D. 2005b, Minor Planet Bulletin, 32, 4

Warner, B. D. 2006a, Minor Planet Bulletin, 33, 58

Warner, B. D. 2006b, Minor Planet Bulletin, 33, 35

Warner, B. D. 2007, Minor Planet Bulletin, 34, 72

Warner, B. D. 2008a, Minor Planet Bulletin, 35, 56

Warner, B. D. 2008b, Minor Planet Bulletin, 35, 163

Warner, B. D. 2009a, Minor Planet Bulletin, 36, 109

Warner, B. D. 2009b, Minor Planet Bulletin, 36, 172

Warner, B. D. 2011a, Minor Planet Bulletin, 38, 52

Warner, B. D. 2011b, Minor Planet Bulletin, 38, 63

Warner, B. D. 2011c, Minor Planet Bulletin, 38, 96

Warner, B. D., Harris, A. W., \& Pravec, P. 2009, Icarus, 202, 134

Yeung, K. W. 2006, Minor Planet Bulletin, 33, 49

Yoshida, F., Dermawan, B., Nakamura, T., et al. 2005, Abstr. IAU Symp., 229, 82

1 Astronomical Institute, Faculty of Mathematics and Physics, Charles University in Prague, V Holešovičkách 2, 18000 Prague, Czech Republic

e-mail: hanus. home@gmail . com

2 Astronomical Observatory Institute, Faculty of Physics, A. Mickiewicz University, Słoneczna 36, 60-286 Poznań, Poland

3 Palmer Divide Observatory, 17995 Bakers Farm Rd., Colorado Springs, CO 80908, USA

44438 Organ Mesa Loop, Las Cruces, NM 88011, USA

5 Goat Mountain Astronomical Research Station, 11355 Mount Johnson Court, Rancho Cucamonga, CA 91737, USA

6 Geneva Observatory, 1290 Sauverny, Switzerland

7 European Space Astronomy Centre, Spain, PO Box 78, 28691 Villanueva de la Cañada, Madrid, Spain

8 Astronomical Institute of the Academy of Sciences, Fričova 298, 25165 Ondřejov, Czech Republic

9 Observatoire de Bédoin, 47 rue Guillaume Puy, 84000 Avignon, France

10 Observatoire de Chinon, Mairie de Chinon, 37500 Chinon, France

11 Courbes de rotation d'astéroïdes et de comètes, CdR

12 Association T60, 14 avenue Édouard Belin, 31400 Toulouse, France

13 Harfleur, France

14 Observatoire des Engarouines, 84570 Mallemort-du-Comtat, France

15 Collonges Observatory, 90 allée des résidences, 74160 Collonges, France

16 Paris and Saint-Savinien, France

17139 Antibes, France

18 Via M. Rosa, 1, 00012 Colleverde di Guidonia, Rome, Italy

19947 Saint-Sulpice, France

20 IMCCE - Paris Observatory - UMR 8028 CNRS, 77 Av. DenfertRochereau, 75014 Paris, France

21 A90 San Gervasi, Spain

22 l'Observatoire de Cabris, 408 chemin Saint Jean Pape, 06530 Cabris, France

23929 Blackberry Observatory, USA

24 Plateau du Moulin à Vent, St-Michel l'Observatoire, France

25 J80 Saint-Hélène, France

26 B13 Tradate, Italy

27138 Village-Neuf, France

28 TASS $=$ The Amateur Sky Survey

29 Shed of Science Observatory, 5213 Washburn Ave. S, Minneapolis, MN 55410, USA

30 Association AstroQueyras, 05350 Saint-Véran, France

31 Association des Utilisateurs de Détecteurs Électroniques (AUDE), France

32 Observatoire du Bois de Bardon, 16110 Taponnat, France

33 Dark Cosmology Centre, Niels Bohr Institute, University of Copenhagen, Juliane Maries Vej 30, 2100 Copenhagen, Denmark

34 Nordic Optical Telescope, Apartado 474, 38700 Santa Cruz de La Palma, Santa Cruz de Tenerife, Spain

35 Hamanowa Astronomical Observatory, Hikarigaoka 4-34, Motomiya, Fukushima, Japan 
36 Institute of Planetary Research, German Aerospace Center, Rutherfordstrasse 2, 12489, Berlin, Germany

37 Hunters Hill Observatory, 7 Mawalan Street, Ngunnawal ACT 2913, Australia

38056 Skalnaté Pleso, Slovakia

39 A83 Jakokoski, Finland

40 Astrophysics Division, Institute of Physics, Jan Kochanowski University, Świętokrzyska 15, 25-406 Kielce, Poland

41 Université de Toulouse, UPS-OMP, IRAP, 31400 Toulouse, France

42 CNRS, IRAP, 14 avenue Édouard Belin, 31400 Toulouse, France

43980 Antelope Drive West, Bennett, CO 80102, USA

44 LESIA-Observatoire de Paris, CNRS, UPMC Univ. Paris 06, Univ. Paris-Diderot, 5 place Jules Janssen, 92195 Meudon, France

45 Stazione Astronomica di Sozzago, 28060 Sozzago, Italy

${ }^{46}$ Forte Software, Os. Jagiełły 28/28 60-694 Poznań, Poland

47 SUPA (Scottish Universities Physics Alliance), Institute for Astronomy, University of Edinburgh, Royal Observatory, Edinburgh, EH9 3HJ, UK

48 Club d'Astronomie Lyon Ampère, 37 rue Paul Cazeneuve, 69008 Lyon, France

49174 Nyrölä, Finland

50 Observatorio Montcabre, C/Jaume Balmes 24, 08348 Cabrils, Barcelona, Spain

51 Observatori Astronómico de Mallorca, Camí de l'Observatori, s/n 07144 Costitx, Mallorca, Spain
${ }_{53}$ Kingsgrove, NSW, Australia

53 Mt. Suhora Observatory, Pedagogical University, Podchorążych 2, 30-084, Cracow, Poland

${ }^{54}$ University of Helsinki, Department of Physics, PO Box 64, 00014 Helsinki

55 Department of Earth, Atmospheric, and Planetary Sciences, Massachusetts Institute of Technology, Cambridge, MA 02139, USA

562 rue des Écoles, 34920 Le Crès, France

57 F.-X. Bagnoud Observatory, 3961 St.-Luc, Switzerland

58 Blauvac Observatory, 84570 St.-Estéve, France

59 Observatoire de la Côte d'Azur, BP 4229, 06304 Nice Cedex 4, France

60 Observatoire de Paris-Meudon, LESIA, 92190 Meudon, France

61143 Gnosca, Switzerland

62 DeKalb Observatory, 2507 CR 60, Auburn, IN 46706, USA

63181 Les Makes, la Réunion, France

64 CNRS-LKB-École Normale Supérieure - UMR 8552 - 24 rue Lhomond, 75005 Paris, France

65 ANS Collaboration, c/o Osservatorio Astronomico di Padova, Sede di Asiago, 36032 Asiago (VI), Italy

66 Institute of Astronomy, Karazin Kharkiv National University, Sums'ka 35, 61022 Kharkiv, Ukraine

67 Observatoire Francois-Xavier Bagnoud, 3961 St.-Luc, Switzerland

Pages 11 to 16 are available in the electronic edition of the journal at http://wWw . aanda. org 
J. Hanuš et al.: Asteroids' physical models

Table 3. Observations used for the successful model determinations that are not included in the UAPC.

\begin{tabular}{|c|c|c|c|c|}
\hline & Asteroid & Date & Observer & Observatory (MPC code) \\
\hline \multirow[t]{6}{*}{11} & Parthenope & $20085-20089$ & Warner & Palmer Divide Observatory (716) \\
\hline & & $20087-20087$ & Pilcher $^{b}$ & Organ Mesa Observatory (G50) \\
\hline & & $200911-20101$ & Pilcher (2010) & \\
\hline & & $20112-20115$ & Pilcher (2011a) & \\
\hline & & $20113-20113$ & Audejean & Observatoire de Chinon, France (B92) \\
\hline & & $20114-20114$ & Naves & Observatorio Montcabre (213) \\
\hline \multirow[t]{4}{*}{25} & Phocaea & 2006 10-2006 10 & Buchheim & Altimira Observatory, USA (G76) \\
\hline & & 20061021.9 & $\begin{array}{l}\text { Strajnic, Grangeon, Coupier, Godon, Roche } \\
\text { Danavaro, Dalmas, Bayol, Behrend }\end{array}$ & Haute-Provence Observatory, France (511) \\
\hline & & $20081-20094$ & Pilcher (2009a) & \\
\hline & & 2010 9-2010 12 & Pilcher (2011b) & \\
\hline \multirow[t]{5}{*}{72} & Feronia & $20043-20044$ & Bernasconi & Les Engarouines Observatory, France (A14) \\
\hline & & $20057-20058$ & Bernasconi & Les Engarouines Observatory, France (A14) \\
\hline & & 2007120.9 & Coliac & Observatoire Farigourette, France \\
\hline & & $20113-20114$ & Marciniak & Borowiec, Poland (187) \\
\hline & & 201159.9 & Hirsch & Borowiec, Poland (187) \\
\hline \multirow[t]{4}{*}{147} & Protogeneia & 2004 11-2004 12 & Buchheim (2005) & \\
\hline & & 200514.9 & Roy & Blauvac Observatory, France (627) \\
\hline & & $20051-20051$ & Bernasconi & Les Engarouines Observatory, France (A14) \\
\hline & & 2008529.7 & Higgins $^{a}$ & Hunters Hill Observatory, Ngunnawal (E14) \\
\hline \multirow[t]{2}{*}{149} & Medusa & $201010-201011$ & Pilcher (2011b) & \\
\hline & & $201011-201012$ & Martin & Tzec Maun Observatory, Mayhill (H10) \\
\hline \multirow[t]{3}{*}{157} & Dejanira & $20053-20053$ & Poncy & Le Crés, France (177) \\
\hline & & $20054-20055$ & Warner (2005a) & \\
\hline & & $200812-20092$ & Pilcher (2009c) & \\
\hline 166 & Rhodope & $201012-20111$ & Conjat & Cabris, France \\
\hline \multirow[t]{2}{*}{178} & Belisana & $20074-20077$ & Oey \& Krajewski (2008) & \\
\hline & & 2008 9-2008 10 & Pilcher et al. (2009) & \\
\hline 183 & Istria & 2004214.1 & Bernasconi & Les Engarouines Observatory, France (A14) \\
\hline \multirow[t]{9}{*}{193} & Ambrosia & $20094-20094$ & Warner (2009b) & \\
\hline & & 19991015.0 & Hirsch & Borowiec, Poland (187) \\
\hline & & $20054-20054$ & Kaminski & Borowiec, Poland (187) \\
\hline & & 200543.9 & Marciniak & Borowiec, Poland (187) \\
\hline & & $20054-20054$ & Hirsch & Borowiec, Poland (187) \\
\hline & & $20093-20093$ & Audejean & Observatoire de Chinon, France (B92) \\
\hline & & $20094-20095$ & Hirsch & Borowiec, Poland (187) \\
\hline & & 2009429.9 & Kaminski & Borowiec, Poland (187) \\
\hline & & 2010419.1 & Borczyk & SAAO, Sutherland, South Africa \\
\hline \multirow[t]{10}{*}{199} & Byblis & $20033-20034$ & Casulli & Vallemare di Bordona, Italy (A55) \\
\hline & & $20035-20035$ & Bernasconi & Les Engarouines Observatory, France (A14) \\
\hline & & $200510-200510$ & Roy & Blauvac Observatory, France (627) \\
\hline & & $200510-200510$ & Casulli & Vallemare di Bordona, Italy (A55) \\
\hline & & $200511-200511$ & Stoss, Nomen, Sanchez, Behrend & OAM, Mallorca (620) \\
\hline & & 20051120.9 & Farroni & \\
\hline & & 2006 12-2006 12 & Roy & Blauvac Observatory, France (627) \\
\hline & & 200829.1 & Manzini & Stazione Astronomica di Sozzago, Italy (A12) \\
\hline & & 2011924.1 & Sobkowiak & Borowiec, Poland (187) \\
\hline & & $201111-201111$ & Marciniak & Borowiec, Poland (187) \\
\hline & Stephania & 2004 10-2004 10 & Koff & Antelope Hills Observatory, Bennett (H09) \\
\hline \multirow{4}{*}{\multicolumn{2}{|c|}{222 Lucia }} & 1999418.2 & Warner & Palmer Divide Observatory (716) \\
\hline & & 2008 12-2008 12 & Stephens (2009a) & \\
\hline & & $20104-20105$ & Audejean & Observatoire de Chinon, France (B92) \\
\hline & & $20104-20104$ & Bosch & Collonges Observatory, France (178) \\
\hline \multirow{10}{*}{\multicolumn{2}{|c|}{242 Kriemhild }} & $20047-20047$ & Bosch & Collonges Observatory, France (178) \\
\hline & & $20048-20048$ & Warner (2005b) & \\
\hline & & $20049-20049$ & Rinner & Ottmarsheim Observatory, France (224) \\
\hline & & 2005117.9 & Roy & Blauvac Observatory, France (627) \\
\hline & & $20071-20071$ & Bembrick et al. (2007) & \\
\hline & & $20098-20098$ & Audejean & Observatoire de Chinon, France (B92) \\
\hline & & $20108-20113$ & Marciniak & Borowiec, Poland (187) \\
\hline & & 20101010.1 & T. Michałowski & Borowiec, Poland (187) \\
\hline & & $201111-20121$ & Marciniak & Borowiec, Poland (187) \\
\hline & & 20111113.1 & Sobkowiak & Borowiec, Poland (187) \\
\hline
\end{tabular}

Notes. ${ }^{(a)}$ On line at http://www.david-higgins.com/Astronomy/asteroid/lightcurves.htm; ${ }^{(b)}$ On line at http://aslc-nm.org/ Pilcher.html; ${ }^{(c)}$ Observations, reductions, and calibration methods are described in Polishook \& Brosch (2008, 2009). 
Table 3. continued.

\begin{tabular}{|c|c|c|c|c|}
\hline & Asteroid & Date & Observer & Observatory (MPC code) \\
\hline \multirow[t]{6}{*}{257} & 7 Silesia & $200412-200412$ & Casulli, Behrend & Vallemare di Bordona, Italy (A55) \\
\hline & & $200412-20051$ & Roy & Blauvac Observatory, France (627) \\
\hline & & 2005131.1 & Starkey & DeKalb Observatory, USA (H63) \\
\hline & & 2005121.1 & $\begin{array}{l}\text { Strajnic, Paulo, Wagrez, Jade, } \\
\text { Rocca, Del Freo, Behrend }\end{array}$ & Haute-Provence Observatory, France (511) \\
\hline & & $200512-20061$ & Roy & Blauvac Observatory, France (627) \\
\hline & & $200512-200512$ & Antonini & Observatoire de Bédoin, France (132) \\
\hline \multirow[t]{2}{*}{260} & 0 Huberta & $20053-20053$ & Roy & Blauvac Observatory, France (627) \\
\hline & & $20077-20078$ & Roy & Blauvac Observatory, France (627) \\
\hline \multirow[t]{2}{*}{272} & 2 Antonia & $200712-20081$ & Pilcher (2008) & \\
\hline & & $201110-201110$ & S. Fauvaud, M. Fauvaud & Observatoire du Bois de Bardon, France \\
\hline 281 & 1 Lucretia & $201110-201110$ & S.Fauvaud, M. Fauvaud & Observatoire du Bois de Bardon, France \\
\hline 290 & Bruna & $20083-20084$ & Pilcher (2009b) & \\
\hline \multirow[t]{9}{*}{297} & 7 Caecilia & 2004 11-2004 12 & Roy & Blauvac Observatory, France (627) \\
\hline & & $20061-20061$ & Manzini & Stazione Astronomica di Sozzago, Italy (A12) \\
\hline & & 2006111.0 & Antonini & Observatoire de Bédoin, France (132) \\
\hline & & 2006113.1 & Roy & Blauvac Observatory, France (627) \\
\hline & & 20091211.8 & Salom, Esteban & Caimari (B81) \\
\hline & & $20112-20113$ & Marciniak & Borowiec, Poland (187) \\
\hline & & 2012130.2 & Marciniak & Borowiec, Poland (187) \\
\hline & & 2012131.2 & Polinska & Borowiec, Poland (187) \\
\hline & & $20122-20123$ & Hirsch & Borowiec, Poland (187) \\
\hline \multirow[t]{17}{*}{345} & 5 Tercidina & $20029-200210$ & Barbotin & Villefagnan Observatory, France \\
\hline & & 2002 9-2002 12 & Bernasconi & Les Engarouines Observatory, France (A14) \\
\hline & & 2002 9-2002 10 & Rinner & Ottmarsheim Observatory, France (224) \\
\hline & & $20029-20029$ & Starkey, Bernasconi & Les Engarouines Observatory, France (A14) \\
\hline & & $20029-20029$ & Waelchli, Revaz & F.-X. Bagnoud Observatory, Switzerland (175) \\
\hline & & 2002101.1 & Michelet & \\
\hline & & 2002105.2 & Barbotin & Villefagnan Observatory, France \\
\hline & & 20021122.9 & Bosch & Collonges Observatory, France (178) \\
\hline & & $200211-200212$ & Starkey & DeKalb Observatory, USA (H63) \\
\hline & & $20044-20045$ & Bernasconi & Les Engarouines Observatory, France (A14) \\
\hline & & $20044-20045$ & Roy & Blauvac Observatory, France (627) \\
\hline & & $20058-20058$ & Bernasconi & Les Engarouines Observatory, France (A14) \\
\hline & & 2005827.0 & Stoss, Nomen, Sanchez, Behrend & OAM, Mallorca (620) \\
\hline & & 200598.0 & Farroni & \\
\hline & & 200875.0 & Trégon, Leroy & Pic du Midi Observatory (586) \\
\hline & & $20098-200910$ & Naves & Observatorio Montcabre (213) \\
\hline & & 2011422.9 & Sobkowiak & Borowiec, Poland (187) \\
\hline \multirow[t]{3}{*}{352} & 2 Gisela & 2002108.7 & Droege & \\
\hline & & 2004213.1 & Bernasconi, Klotz, Behrend & Haute-Provence Observatory, France (511) \\
\hline & & $20057-20058$ & Bernasconi & Les Engarouines Observatory, France (A14) \\
\hline \multirow[t]{5}{*}{371} & 1 Bohemia & $20016-20043$ & Buchheim et al. (2004) & \\
\hline & & 200692.0 & Bernasconi & Les Engarouines Observatory, France (A14) \\
\hline & & $20118-201111$ & Marciniak & Borowiec, Poland (187) \\
\hline & & 2011112.9 & W. Ogłoza & Mnt. Suhora, Poland \\
\hline & & 20111130.9 & Santana-Ros & Borowiec, Poland (187) \\
\hline \multirow[t]{2}{*}{390} & Alma & $20048-20048$ & Stephens (2005b) & \\
\hline & & $20088-200810$ & Roy & Blauvac Observatory, France (627) \\
\hline \multirow[t]{5}{*}{403} & 3 Cyane & 2001129.1 & Brunetto & Le Florian, France (139) \\
\hline & & $200112-200112$ & Bernasconi & Les Engarouines Observatory, France (A14) \\
\hline & & 20011222.2 & Cooney & \\
\hline & & 2005101.0 & Bernasconi & Les Engarouines Observatory, France (A14) \\
\hline & & $20072-20072$ & Roy & Blauvac Observatory, France (627) \\
\hline \multirow[t]{12}{*}{404} & 4 Arsinoe & $19993-19994$ & Kryszczynska & Borowiec, Poland (187) \\
\hline & & 1999319.0 & Hirsch & Borowiec, Poland (187) \\
\hline & & 1999320.0 & T. Michałowski & Borowiec, Poland (187) \\
\hline & & 2001 10-2001 10 & S. Fauvaud, Heck, Santacana, Wucher & Pic de Château-Renard Observatory \\
\hline & & $200111-200112$ & Bernasconi & Les Engarouines Observatory, France (A14) \\
\hline & & $20034-20034$ & Roy & Blauvac Observatory, France (627) \\
\hline & & 2005810.1 & Fagas & Borowiec, Poland (187) \\
\hline & & 2005 10-200510 & Hirsch & Borowiec, Poland (187) \\
\hline & & 2005 10-200511 & Roy & Blauvac Observatory, France (627) \\
\hline & & $200611-20071$ & Fagas & Borowiec, Poland (187) \\
\hline & & $20071-20074$ & Marciniak & Borowiec, Poland (187) \\
\hline & & 2007217.0 & Hirsch & Borowiec, Poland (187) \\
\hline
\end{tabular}


Table 3. continued.

\begin{tabular}{|c|c|c|c|c|}
\hline & Asteroid & Date & Observer & Observatory (MPC code) \\
\hline & & $20074-20074$ & Kaminski & Borowiec, Poland (187) \\
\hline & & 2007422.0 & Kankiewicz & Kielce, Poland (B02) \\
\hline & & $20086-20086$ & Marciniak & SAAO, Sutherland, South Africa \\
\hline & & $20098-200910$ & Marciniak & SAAO, Sutherland, South Africa \\
\hline & & 2009927.0 & Hirsch & Borowiec, Poland (187) \\
\hline & & 20091030.0 & Polinska & Borowiec, Poland (187) \\
\hline & & 2009123.0 & Kaminski & Borowiec, Poland (187) \\
\hline & & 2010125.0 & Sobkowiak & Borowiec, Poland (187) \\
\hline & & $20111-20115$ & Marciniak & Borowiec, Poland (187) \\
\hline & & $20113-20113$ & Hirsch & Borowiec, Poland (187) \\
\hline \multirow[t]{3}{*}{406} & Erna & 2005 9-2005 10 & Casulli & Vallemare di Bordona, Italy (A55) \\
\hline & & $200511-200511$ & Crippa, Manzini & Stazione Astronomica di Sozzago, Italy (A12) \\
\hline & & $200511-200511$ & Poncy & Le Crés, France (177) \\
\hline \multirow[t]{10}{*}{441} & Bathilde & $20031-20031$ & Roy & Blauvac Observatory, France (627) \\
\hline & & $20032-20032$ & Bernasconi & Les Engarouines Observatory, France (A14) \\
\hline & & $20032-20033$ & Vagnozzi, Cristofanelli, Paiella & Santa Lucia Stroncone (589) \\
\hline & & $20057-20058$ & Bernasconi & Les Engarouines Observatory, France (A14) \\
\hline & & 20061211.9 & Poncy & Le Crés, France (177) \\
\hline & & 2010 9-2010 10 & Marciniak & Borowiec, Poland (187) \\
\hline & & 2010104.8 & Kaminski & Borowiec, Poland (187) \\
\hline & & 2010109.9 & T. Michałowski & Borowiec, Poland (187) \\
\hline & & 20111014.0 & Sobkowiak & Borowiec, Poland (187) \\
\hline & & $201110-201111$ & Marciniak & Borowiec, Poland (187) \\
\hline \multirow[t]{2}{*}{507} & Laodica & $20018-20018$ & Charbonnel & Durtal (949) \\
\hline & & $20018-20019$ & Leyrat & \\
\hline \multirow[t]{2}{*}{509} & Iolanda & $199610-199610$ & López-González \& Rodríguez (2000) & \\
\hline & & 200068.3 & Koff \& Brincat (2000) & \\
\hline \multirow[t]{2}{*}{512} & Taurinensis & $200412-20051$ & Poncy & Le Crés, France (177) \\
\hline & & 200515.0 & Correia & Haute-Provence Observatory, France (511) \\
\hline 528 & Rezia & $20113-20113$ & Mottola & \\
\hline \multirow[t]{3}{*}{531} & Zerlina & 200262.9 & Christophe & \\
\hline & & 2007 9-2007 10 & Brinsfield (2008b) & \\
\hline & & $20113-20116$ & Pilcher \& Brinsfield (2011) & \\
\hline 543 & Charlotte & 2006 11-2006 12 & Poncy & Le Crés, France (177) \\
\hline \multirow[t]{2}{*}{572} & Rebekka & $20072-20072$ & Warner (2007) & \\
\hline & & $20098-20098$ & Audejean & Observatoire de Chinon, France (B92) \\
\hline \multirow[t]{4}{*}{578} & Happelia & 2006 12-2006 12 & Leroy & Uranoscope, France (A07) \\
\hline & & $20084-20084$ & Warner (2008b) & \\
\hline & & $201011-201012$ & Antonini & Observatoire de Bédoin, France (132) \\
\hline & & $20122-20124$ & Mottola, Hellmich & \\
\hline \multirow[t]{11}{*}{600} & Musa & 200146.0 & Hirsch & Borowiec, Poland (187) \\
\hline & & 2001429.0 & Colas & Pic du Midi Observatory (586) \\
\hline & & $20052-20053$ & Bernasconi & Les Engarouines Observatory, France (A14) \\
\hline & & $20053-20054$ & Hirsch & Borowiec, Poland (187) \\
\hline & & 200541.0 & Marciniak & Borowiec, Poland (187) \\
\hline & & 2007 10-2007 10 & S. Fauvaud, Santacana, M. Fauvaud & Pic du Midi Observatory (586) \\
\hline & & 2009325.8 & Kaminski & Borowiec, Poland (187) \\
\hline & & 2009330.9 & Marciniak & Borowiec, Poland (187) \\
\hline & & $20104-20106$ & Marciniak & Borowiec, Poland (187) \\
\hline & & $201111-201111$ & Marciniak & Borowiec, Poland (187) \\
\hline & & 20111129.8 & Hirsch & Borowiec, Poland (187) \\
\hline 669 & Kypria & $20063-20064$ & Bernasconi & Les Engarouines Observatory, France (A14) \\
\hline 708 & Raphaela & $20072-20072$ & Warner (2007) & \\
\hline \multirow[t]{10}{*}{725} & Amanda & 20021212.8 & Marciniak & Borowiec, Poland (187) \\
\hline & & 20021231.8 & T. Michałowski & Borowiec, Poland (187) \\
\hline & & 2006 10-2006 10 & S. Fauvaud, Santacana, Sareyan, Wucher & Pic de Château-Renard Observatory \\
\hline & & 20061030.1 & Hirsch & Borowiec, Poland (187) \\
\hline & & $20098-20098$ & Marciniak & SAAO, Sutherland, South Africa \\
\hline & & $201010-201010$ & Audejean & Observatoire de Chinon, France (B92) \\
\hline & & 20101031.0 & Marciniak & Borowiec, Poland (187) \\
\hline & & 201233.1 & Marciniak & Borowiec, Poland (187) \\
\hline & & $20123-20123$ & Hirsch & Borowiec, Poland (187) \\
\hline & & 2012410.1 & Oszkiewicz, Geier & NOT, La Palma, Canary Islands \\
\hline \multirow[t]{2}{*}{731} & Sorga & $20054-20054$ & Warner (2005a) & \\
\hline & & $20092-20092$ & Warner (2009a) & \\
\hline 732 & Tjilaki & $20043-20044$ & Bernasconi & Les Engarouines Observatory, France (A14) \\
\hline 787 & Moskva & $19995-19995$ & Warner (2011a) & \\
\hline
\end{tabular}


Table 3. continued.

\begin{tabular}{|c|c|c|c|c|}
\hline & Asteroid & Date & Observer & Observatory (MPC code) \\
\hline & & $20034-20035$ & Husarik, Behrend & Skalnate Pleso, Slovakia (056) \\
\hline & & $20035-20035$ & Bernasconi & Les Engarouines Observatory, France (A14) \\
\hline & & $20048-20048$ & Bernasconi & Les Engarouines Observatory, France (A14) \\
\hline & & $20115-20115$ & Audejean & Observatoire de Chinon, France (B92) \\
\hline & & $20115-20115$ & Morelle & Observatoire Farigourette, France \\
\hline 792 & Metcalfa & $20107-20108$ & Roy & Blauvac Observatory, France (627) \\
\hline \multirow[t]{3}{*}{803} & Picka & 20061210.8 & Bosch & Collonges Observatory, France (178) \\
\hline & & $20074-20074$ & Antonini & Observatoire de Bédoin, France (132) \\
\hline & & $201011-201011$ & Antonini & Observatoire de Bédoin, France (132) \\
\hline 812 & Adele & $200210-200210$ & Roy & Blauvac Observatory, France (627) \\
\hline \multirow{3}{*}{816} & Juliana & $20054-20054$ & Stephens (2005a) & \\
\hline & & 2005 5-2005 6 & Conjat & Cabris, France \\
\hline & & $20103-20103$ & Conjat & Cabris, France \\
\hline \multirow[t]{12}{*}{852} & Wladilena & 2003223.2 & J. Michałowski & Borowiec, Poland (187) \\
\hline & & 2003224.2 & Marciniak & Borowiec, Poland (187) \\
\hline & & 2003226.2 & T. Michałowski & Borowiec, Poland (187) \\
\hline & & $20075-20075$ & Marciniak & SAAO, Sutherland, South Africa \\
\hline & & 2008822.2 & M. J. Michałowski & NOT, La Palma, Canary Islands \\
\hline & & $200810-20091$ & Kaminski & Borowiec, Poland (187) \\
\hline & & 2008 9-2008 10 & Marciniak & Borowiec, Poland (187) \\
\hline & & 2008 12-2009 1 & Sobkowiak & Borowiec, Poland (187) \\
\hline & & $20102-20103$ & Antonini & Observatoire de Bédoin, France (132) \\
\hline & & $20103-20105$ & Marciniak & Borowiec, Poland (187) \\
\hline & & $20103-20103$ & Polishook $(2012)^{c}$ & Wise Observatory, Mitzpeh Ramon (097) \\
\hline & & $20103-20104$ & Sobkowiak & Borowiec, Poland (187) \\
\hline 857 & Glasenapia & 20061223.0 & Poncy & Le Crés, France (177) \\
\hline \multirow[t]{8}{*}{867} & Kovacia & 20061122.8 & Crippa, Manzini & Stazione Astronomica di Sozzago, Italy (A12) \\
\hline & & $20081-20082$ & Roy & Blauvac Observatory, France (627) \\
\hline & & 200828.9 & Casulli & Vallemare di Bordona, Italy (A55) \\
\hline & & 200829.0 & Colas & Pic du Midi Observatory (586) \\
\hline & & $20082-20082$ & Manzini & Stazione Astronomica di Sozzago, Italy (A12) \\
\hline & & $20082-20082$ & Leroy & Uranoscope, France (A07) \\
\hline & & $20082-20082$ & Demeautis & Village-Neuf Observatory, France (138) \\
\hline & & $20082-20083$ & Coliac & Observatoire Farigourette, France \\
\hline \multirow[t]{2}{*}{874} & Rotraut & $20027-20027$ & Charbonnel & Durtal (949) \\
\hline & & 2002816.0 & Rinner & Ottmarsheim Observatory, France (224) \\
\hline \multirow[t]{2}{*}{875} & Nymphe & $20037-20037$ & Warner (2011c) & \\
\hline & & $20037-20037$ & Roy & Blauvac Observatory, France (627) \\
\hline 900 & Rosalinde & 2007519.0 & Roy & Blauvac Observatory, France (627) \\
\hline \multirow[t]{12}{*}{994} & Otthild & 2001922.0 & Velichko, T. Michałowski & Kharkov (101) \\
\hline & & $200110-200110$ & J. Michałowski & Borowiec, Poland (187) \\
\hline & & $200110-200110$ & Conjat & Cabris, France \\
\hline & & $200111-200111$ & T. Michałowski & Borowiec, Poland (187) \\
\hline & & $200111-200111$ & Kwiatkowski & Borowiec, Poland (187) \\
\hline & & $20058-200511$ & Stoss, Nomen, Sanchez, Behrend & OAM, Mallorca (620) \\
\hline & & 2005101.9 & Bernasconi & Les Engarouines Observatory, France (A14) \\
\hline & & $200510-200510$ & Fagas & Borowiec, Poland (187) \\
\hline & & 20051019.9 & T. Michałowski & Borowiec, Poland (187) \\
\hline & & 2007226.9 & $\begin{array}{c}\text { S. Fauvaud, Esseiva, Michelet, } \\
\text { Saguin, Sareyan }\end{array}$ & Pic de Château-Renard Observatory \\
\hline & & 2011319.9 & Polinska & Borowiec, Poland (187) \\
\hline & & 2011329.8 & Marciniak & Borowiec, Poland (187) \\
\hline 1056 & Azalea & $20042-20042$ & Klotz, Behrend & Haute-Provence Observatory, France (511) \\
\hline \multirow[t]{14}{*}{1089} & Tama & $200312-20043$ & Roy & Blauvac Observatory, France (627) \\
\hline & & $200312-20042$ & Rinner & Ottmarsheim Observatory, France (224) \\
\hline & & $20041-20041$ & Antonini & Observatoire de Bédoin, France (132) \\
\hline & & $20041-20041$ & Sposetti, Behrend & Gnosca Observatory, Switzerland (143) \\
\hline & & 200414.9 & Klotz & Haute-Provence Observatory, France (511) \\
\hline & & $20041-20041$ & Lecacheux, Colas & Pic du Midi Observatory (586) \\
\hline & & 2004122.8 & Colas & Pic du Midi Observatory (586) \\
\hline & & 2004126.9 & Michelsen, Augustesen, Masi & Brorfelde (054) \\
\hline & & $20041-20041$ & Cotrez, Behrend & Saint-Hélène Observatory, France (J80) \\
\hline & & $20041-20042$ & Durkee & Shed of Science Observatory, USA (H39) \\
\hline & & 200427.9 & Bernasconi & Les Engarouines Observatory, France (A14) \\
\hline & & 200429.8 & Coloma & Sabadell (619) \\
\hline & & $20042-20042$ & Oksanen & Nyrölä Observatory, Finland (174) \\
\hline & & 2004211.9 & Itkonen, Pääkkönen & Jakokoski Observatory, Finland (A83) \\
\hline
\end{tabular}


Table 3. continued.

\begin{tabular}{|c|c|c|c|c|}
\hline \multicolumn{2}{|r|}{ Asteroid } & \multirow{2}{*}{$\begin{array}{l}\text { Date } \\
2004215.0\end{array}$} & \multirow{2}{*}{ Observer } & Observatory (MPC code) \\
\hline & & & & \\
\hline & & 2004220.9 & Demeautis, Matter & Village-Neuf Observatory, France (138) \\
\hline & & 2004224.1 & Barbotin, Cotrez, Cazenave, Laffont & Pic du Midi Observatory (586) \\
\hline & & $20056-20057$ & Stoss, Nomen, Sanchez, Behrend & OAM, Mallorca (620) \\
\hline & & $20057-20058$ & Teng, Behrend & Observatoire Les Makes, France (181) \\
\hline & & $20069-200612$ & Sposetti, Pavic & Gnosca Observatory, Switzerland (143) \\
\hline & & 2006 9-2006 12 & Polishook $(2012)^{c}$ & Wise Observatory, Mitzpeh Ramon (097) \\
\hline & & 20061126.9 & Sposetti, Behrend & Gnosca Observatory, Switzerland (143) \\
\hline & & 200845.1 & Klotz, Strajnic & Haute-Provence Observatory, France (511) \\
\hline & & $20085-20085$ & Roy & Blauvac Observatory, France (627) \\
\hline & & $20085-20085$ & Polishook $(2012)^{c}$ & Wise Observatory, Mitzpeh Ramon (097) \\
\hline & & 2009 10-2009 11 & Polishook $(2012)^{c}$ & Wise Observatory, Mitzpeh Ramon (097) \\
\hline & & $20112-20113$ & Crippa, Manzini & Stazione Astronomica di Sozzago, Italy (A12) \\
\hline 1111 & Reinmuthia & 2007 10-2007 11 & Hiromi Hamanowa, Hiroko Hamanowa & \\
\hline 1126 & Otero & $20082-20082$ & Stephens (2008) & \\
\hline \multirow{2}{*}{1130} & Skuld & 2004122.0 & Colas & Pic du Midi Observatory (586) \\
\hline & & 2009 10-2009 11 & Buchheim (2010) & \\
\hline \multirow[t]{7}{*}{1188} & Gothlandia & 200612.9 & Pallares & Sabadell (619) \\
\hline & & 2006111.9 & Coloma & Agrupación Astronómica de Sabadell, Spain (A90) \\
\hline & & 200622.9 & Coloma, Garcia & Agrupación Astronómica de Sabadell, Spain (A90) \\
\hline & & $20075-20075$ & Antonini & Observatoire de Bédoin, France (132) \\
\hline & & $200812-20091$ & H. Hamanowa, H. Hamanowa & \\
\hline & & $20118-201112$ & Baker et al. (2012) & \\
\hline & & $20119-20119$ & S. Fauvaud, M. Fauvaud & Observatoire du Bois de Bardon, France \\
\hline \multirow{3}{*}{1241} & Dysona & 2002 9-2002 11 & Bosch & Collonges Observatory, France (178) \\
\hline & & 2002102.0 & Brunetto & Le Florian, France (139) \\
\hline & & $20064-20065$ & Oey & Leura $(\mathrm{E} 17)$ \\
\hline \multirow[t]{3}{*}{1249} & Rutherfordia & $20018-20018$ & Bernasconi & Les Engarouines Observatory, France (A14) \\
\hline & & 2008822.0 & Demeautis & Village-Neuf Observatory, France (138) \\
\hline & & $20047-20047$ & Roy & Blauvac Observatory, France (627) \\
\hline \multirow[t]{2}{*}{1317} & Silvretta & $20064-20064$ & Bernasconi & Les Engarouines Observatory, France (A14) \\
\hline & & $200912-20101$ & Ruthroff (2010) & \\
\hline \multirow[t]{5}{*}{1386} & Storeria & $20046-20046$ & Warner (2004) & \\
\hline & & 2004715.0 & Behrend, Klotz & Haute-Provence Observatory, France (511) \\
\hline & & 2004717.0 & Bernasconi & Les Engarouines Observatory, France (A14) \\
\hline & & 2004721.0 & Coloma & Agrupación Astronómica de Sabadell, Spain (A90) \\
\hline & & 2004728.0 & Roy & Blauvac Observatory, France (627) \\
\hline \multirow[t]{2}{*}{1401} & Lavonne & 200888.3 & Durkee & Shed of Science Observatory, USA (H39) \\
\hline & & $20089-20089$ & Antonini & Observatoire de Bédoin, France (132) \\
\hline 1432 & Ethiopia & 2007 7-2007 9 & Oey (2008) & \\
\hline \multirow[t]{4}{*}{1436} & Salonta & $20078-20079$ & Warner (2008a) & \\
\hline & & $200710-200710$ & Antonini & Observatoire de Bédoin, France (132) \\
\hline & & $200811-200811$ & Antonini & Observatoire de Bédoin, France (132) \\
\hline & & 20081127.8 & Roy & Blauvac Observatory, France (627) \\
\hline \multirow[t]{2}{*}{1472} & Muonio & 2008 9-2008 9 & Stephens (2009b) & \\
\hline & & $200810-200810$ & Higgins $^{a}$ & Hunters Hill Observatory, Ngunnawal (E14) \\
\hline 1490 & Limpopo & $20058-20058$ & Bernasconi & Les Engarouines Observatory, France (A14) \\
\hline 1495 & Helsinki & $20064-20065$ & Oey et al. (2007) & \\
\hline & & 200664.0 & Payet, Teng, Leonie, Behrend & Observatoire Les Makes, France (181) \\
\hline & & $20066-20067$ & Teng, Behrend & Observatoire Les Makes, France (181) \\
\hline & & $20119-20119$ & S. Fauvaud, M. Fauvaud & Observatoire du Bois de Bardon, France \\
\hline 1518 & Rovaniemi & $20091-20091$ & Warner (2009a) & \\
\hline & & $20091-20091$ & Roy & Blauvac Observatory, France (627) \\
\hline 1528 & Conrada & $20085-20085$ & Warner (2008b) & \\
\hline 1554 & Yugoslavia & $20074-20074$ & Higgins (2008) & \\
\hline 1559 & Kustaanheimo & $20053-20053$ & Bernasconi & Les Engarouines Observatory, France (A14) \\
\hline 1572 & Posnania & 1993 9-1999 11 & Michałowski et al. (2001) & \\
\hline & & $20049-20049$ & Roy & Borowiec, Poland (187) \\
\hline & & 2010125.1 & Sobkowiak & Borowiec, Poland (187) \\
\hline & & $20112-20112$ & Kaminski & Borowiec, Poland (187) \\
\hline & & 201128.8 & Marciniak & Borowiec, Poland (187) \\
\hline & & $20122-20123$ & Roy & Blauvac Observatory, France (627) \\
\hline 1607 & Mavis & 2007 9-2007 9 & Oey (2008) & \\
\hline 1630 & Milet & $20052-20052$ & Bernasconi & Les Engarouines Observatory, France (A14) \\
\hline 1634 & Ndola & $20069-20069$ & Higgins $^{a}$ & Hunters Hill Observatory, Ngunnawal (E14) \\
\hline 1719 & Jens & $20009-20009$ & Warner (2011b) & \\
\hline & & $20061-20062$ & Bernasconi & Les Engarouines Observatory, France (A14) \\
\hline
\end{tabular}


Table 3. continued.

\begin{tabular}{|c|c|c|c|c|}
\hline & Asteroid & Date & Observer & Observatory (MPC code) \\
\hline 1785 & Wurm & $20083-20083$ & Oey (2009) & \\
\hline 1837 & Osita & $20061-20063$ & Roy & Blauvac Observatory, France (627) \\
\hline 1927 & Suvanto & $20052-20052$ & Bernasconi & Les Engarouines Observatory, France (A14) \\
\hline 1933 & Tinchen & 2005314.0 & Roy & Blauvac Observatory, France (627) \\
\hline 1950 & Wempe & 200621.9 & Bernasconi & Les Engarouines Observatory, France (A14) \\
\hline \multirow[t]{4}{*}{1963} & Bezovec & $20051-20051$ & Bernasconi & Les Engarouines Observatory, France (A14) \\
\hline & & $20093-20093$ & Romeuf & \\
\hline & & 200946.9 & Manzini & Stazione Astronomica di Sozzago, Italy (A12) \\
\hline & & 2009 4-2009 4 & Martin & Tzec Maun Observatory, Mayhill (H10) \\
\hline \multirow[t]{2}{*}{2002} & Euler & $20065-20065$ & Koff & Antelope Hills Observatory, Bennett (H09) \\
\hline & & 2007 10-2007 10 & Higgins $^{a}$ & Hunters Hill Observatory, Ngunnawal (E14) \\
\hline 2510 & Shandong & $20068-20069$ & Higgins \& Goncalves (2007) & \\
\hline \multirow[t]{2}{*}{2606} & Odessa & $20082-20082$ & Higgins et al. (2008) & \\
\hline & & 200833.6 & Oey & Leura (E17) \\
\hline \multirow[t]{2}{*}{2709} & Sagan & $20083-20083$ & Higgins et al. (2008) & \\
\hline & & $20111-20112$ & Oey & Leura (E17) \\
\hline \multirow[t]{2}{*}{2839} & Annette & $200510-200511$ & Buchheim (2007) & \\
\hline & & $200512-200512$ & Warner (2006a) & \\
\hline \multirow[t]{3}{*}{2957} & Tatsuo & $20058-20058$ & Bernasconi & Les Engarouines Observatory, France (A14) \\
\hline & & $20058-20059$ & Poncy & Le Crés, France (177) \\
\hline & & $20059-20059$ & Warner (2006b) & \\
\hline 2991 & Bilbo & $20074-20074$ & Higgins $^{a}$ & Hunters Hill Observatory, Ngunnawal (E14) \\
\hline \multirow[t]{4}{*}{3722} & Urata & $200412-200412$ & Antonini & Observatoire de Bédoin, France (132) \\
\hline & & 200693.0 & Manzini & Stazione Astronomica di Sozzago, Italy (A12) \\
\hline & & $20078-20078$ & Roy & Blauvac Observatory, France (627) \\
\hline & & $20078-20078$ & Stephens & Goat Mountain Astronomical Research Station (G79) \\
\hline 5281 & Lindstrom & $20086-20086$ & Brinsfield & Via Capote Sky Observatory, Thousand Oaks (G69) \\
\hline 7517 & 1989 AD & $200711-200711$ & Stephens & Goat Mountain Astronomical Research Station (G79) \\
\hline 8132 & Vitginzburg & $20086-20086$ & Brinsfield (2008a) & \\
\hline \multirow[t]{2}{*}{8359} & 1989 WD & 2009 4-2009 4 & Higgins \& Warner (2009) & \\
\hline & & $20095-20095$ & Brinsfield (2009) & \\
\hline \multirow[t]{2}{*}{10772} & 1990 YM & $20063-20063$ & Koff & Antelope Hills Observatory, Bennett (H09) \\
\hline & & $20064-20064$ & Warner & Palmer Divide Observatory (716) \\
\hline 31383 & $1998 \mathrm{XJ}_{94}$ & $20064-20064$ & Higgins et al. (2006) & \\
\hline
\end{tabular}

